\title{
Application of the adverse outcome pathway framework to predict the toxicity of chemicals in the semiconductor manufacturing industry
}

\author{
Kyung-Taek $\operatorname{Rim}^{1}$ (i)
}

Accepted: 20 April 2021 / Published online: 5 May 2021

(c) The Korean Society of Toxicogenomics and Toxicoproteomics 2021

\begin{abstract}
Background To solve current issues using big data, solve current issues related to the semiconductor and electronics industry, I tried to establish the data for each toxicity mechanism for adverse outcome pathway (AOP) for the exposure.

Objective I planned to increase the efficiency of human hazard assessment by searching, analyzing, and linking test data on the relationship between key events occurred at each level, which are the biological targets of chemicals in semiconductor manufacturing.

Results It was found that 48 kinds of chemicals had 11 AOPs, while 103 chemicals had multiple AOPs, and 26 had case evidence. As a result of AOP analysis, it was found that a total of 320 chemicals had 42 AOPs, and 190 major chemicals corresponded to 11 AOPs. It was found necessary to develop a complex AOP and secure an (inhalation or dermal) exposure scenario for combined exposure at work. As a comparative search (41 out of 190 chemicals) of biomarkers specific to occupational diseases, 12 biomarkers were found to be related to breast cancer. The AOPs for 50 specific chemicals were presented, together with occupational disease-specific AOPs and key events relationship from 50 chemicals, and taxonomic classification for each AOP analysis could be found. With a comparative search, 41 out of 190 chemicals were associated with specific biomarkers for occupational diseases, and $12 \mathrm{mRNA}$ or protein biomarkers were found to be related to breast cancer by cross-validation with the attached Table 24 of the Enforcement Regulations of the OSHAct and the CTD.

Conclusion The mechanism of occupational diseases caused by chemicals was presented, together with pathological preventions. I believe that a strategy is needed to expand the target organization for each chemical by linking with activities, such as work environment measurement, and cooperating with screening items and methods suitable for toxic chemicals, like AOP tools.
\end{abstract}

Keywords Adverse outcome pathway $\cdot$ Application $\cdot$ Chemicals $\cdot$ Semiconductor

\section{Introduction}

\section{Vision and strategy of toxicity testing in the twenty-first century}

The National Research Council of the United States (NRC)'s Toxicology Test for the twenty-first Century: Vision and Strategy (US National Research Council 2007) attempted to study a toxic pathway that further expands in vitro testing, as well as present a new method of computational

Kyung-Taek Rim

rim3249@gmail.com

1 Chemicals Research Bureau, Occupational Safety and Health Research Institute, Korea Occupational Safety and Health Agency, Daejeon, South Korea biology through a paradigm shift. The term "Adverse outcome pathway" (AOP) refers to a biological pathway that induces toxicity and disturbs homeostasis, and a description of toxicity is a description of interactions, including chemical characterization, to explain the effects of major pathways. It includes a targeted study for this purpose, and a dose-response extrapolation to estimate the resulting human exposure. As a conceptual framework for systematizing biological knowledge, AOP consists of a molecular initiating event (MIE), a key event (KE), and an adverse output (AO). Each event represents a biological response, and is termed a key event relation (KER). This AOP concept can identify intuitive risks that can help in the carcinogenicity assessment of chemicals, and the application of the AOP concept to the predictive assessment of carcinogenicity of chemicals, and the usefulness of this technique for cancer prevention, 
are emerging (Kang et al. 2018). MIE is an early event of AOP, representing chemical reactions of molecules, such as ligand-receptor binding or DNA binding. KE is a biological change triggered by a MIE at various levels, and as a special form of KE, AO represents a specific endpoint for biological changes caused by a MIE, and can be reflected in risk assessment or regulatory decision. MIE, KE, and AO are connected by a one-way arrow called a KER, and KER means a causal relationship or interaction between the upstream and downstream KEs, making it easy to guess or extrapolate the state of the lower KE corresponding to the upper KE (OECD 2018).

Each element of the AOP must be based on the weight of evidence (WoE), and the WoE uses information from each source to provide evidence that meets the information requirements. It is a concept that there may be several KEs, which are intermediate steps in one AOP, and each KE may be included in other AOPs (ECHA 2018). AOP leads to AOs that describe the causal relationship of chain biological responses at various levels caused by stressors (Ankley et al. 2010; Ankley and Edwards 2018; Vinken 2013; Villeneuve et al. 2014a, b). Any data from biological reactions (e.g., results of in vivo or in vitro tests, information and biomarkers, etc.) could be applied to AOP (OECD 2012). Therefore, $\mathrm{AOP}$ is a dynamic tool that allows the information to change more accurately as the technology used to observe biological responses develops (Villeneuve et al. 2014a, b). Since the AOP is expressed in a simple sequence, it is easy to intuitively understand the side effects of chemicals; the concept of AOP did not arise suddenly, but could be an evolution of the present concept related to the toxic mechanism (Ankley et al. 2010; Leist et al. 2017). As of August 2018, the AOP concept has 243 AOPs and 1800 KEs registered or under development. This AOP information is freely available in the 'AOP Knowledge-Base (AOP-KB)', a major AOP database managed by the Organization for Economic Cooperation and Development (OECD). This site shares and discusses relevant information among AOP developers. To do this, the OECD began the site in cooperation with the US EPA, the European Community's (EC) joint research center, and the US Army Engineer R\&D Center (ERDC). The AOP$\mathrm{KB}$ is composed of AOPwiki, Effectopedia, Intermediate Effects DB, and AOP Xplorer (ECHA 2018). AOPwiki provides a system that organizes the knowledge and research data for each AOP, KE, KER, and stressors. The Effectopedia is a modeling platform that is designed to develop and apply the AOP. Since each element of the AOP-KB is arranged, it is useful for application in various studies (Villeneuve et al. 2014a, b). The OECD provides comprehensive management for the development and evaluation of AOPs (OECD 2016), which processes are supervised by the OECD Extended Advisory Group on Molecular Screening and Toxicgenomics (EAGMST), and the AOPwiki is the promotion association in accordance with EAGMST guidelines. Since the first AOP, "A pathway initiated by covalent bonds to proteins" was published by the OECD, several reports and guidelines on AOP have been published, and the OECD has provided eight AOP-related publications. As of March, 60 projects are listed in the AOP Development Program Work Plan (OECD 2018).

Several such case studies show how to inform the development of AOP in chemical hazard assessment (Worth et al. 2014). The AOP is a means of providing information on toxic mechanisms, in vitro testing and integrated testing strategies (ITS), and integrated approaches to testing and assessment (IATA), including chemistry and computational based QSAR, and toxicity test results. Recently published OECD Guidelines provide guidance on what information is needed to identify and document AOPs in terms of relevance and suitability (OECD 2013). In addition, the AOP can be used to fill the data gap, and develop toxicity testing strategies by reasonably combining mechanical knowledge related to biotoxicity by nanoparticles according to OECD guidelines, etc. AOPs selected by capturing chemicalinduced toxicity mechanisms can be used to provide predictive modeling and risk assessment for nanomaterial toxicity (Gerloff et al. 2017). In cultured humans (e.g., multiparametric high-throughput screening (HTS) using human lung cells), a fast and cost-effective safe test method is required, and is intended to explain the mechanism responsible for its toxicity. Under genome, a number of adverse effects on manufactured nanomaterials, such as multi-walled carbon nanotubes (MWCNT), can be confirmed, one of which has recently been evaluated as having carcinogenic potential. The AOP is currently being used as a state-of-the-art strategy to analyze the effects of the genome by exposure to manufactured nanoparticles by focusing on diseases (Tanaka et al. 2019). The system for ENM's Health Hazard Assessment (HHRA) has not yet been established. Although rodent carcinogenicity test (for 2 years), clinical pathology and histopathological results have been regarded as 'Golden standards' to reveal their toxicity in animal models, the results from the alternative tests, such as expression analysis and in vivo HTS, is increasing, and there are effective mechanism-based tests to determine the level of exposure to nanoparticles in product development. Although many chemical safety assessment databases, such as PubChem, TOXNET, and INCHEM, are available, these are insufficient to fully assess the safety of chemicals. In general, the hazard/risk evaluation of chemicals is defined and carried out as four processes: hazard identification, dose-response evaluation, exposure evaluation, and risk assessment (US EPA 2018). With the mode of action (MoA) analysis and WoE, in vivo and in vitro tools, and quantitative structure-activity relationships, these tools are based on mathematical statistical models, such as physiology-based toxicokinetic modeling, 
using absorption, distribution, metabolism, and excretion (ADME) (Bessems et al. 2014). Accumulation of adverse events over a long time may lead to genotoxic or non-genetic damage, and increase the possibility of cancer as an endpoint (Cohen and Arnold 2011). Lots of cell abnormalities may occur due to genetic or epigenetic changes in the carcinogenesis process (American Cancer Society 2018). Several international organizations designate and classify carcinogens. For example, the International Agency for Research on Cancer (IARC) classifies carcinogens into five levels (IARC 2018). Since the carcinogenic potential varies from chemical to chemical, it should be understood that it may not cause cancer, depending on the duration and intensity of exposure, and the genetic makeup of the test animal. AOP is the production of information describing molecular occurrence events (MIE), intermediate effects (IE), and toxic manifestations (AO), and many research institutes that aim to create standardized methods to facilitate the collection and retrieval of this information in a consistent way are participating. After the OECD adopted a standard data format for OHT (OECD harmonized templates, a collection of data entry forms for more than 100 endpoints describing chemicals), the intermediate effect (IE) used for hazard evaluation in some situations, the median effects reported by OHT 201 to develop AOPs, OECD EAGMST and WHO IPCS (World Health Organization in accordance with the request of the International Chemical Safety Program), the AOP technology base was formed (OECD 2013).

The application of AOP to occupational health could explore the multi-process chemical knowledge to establish definition, classification, characterization, and hazard evaluation, and the role of MIE research in the development of in vitro and in silico tools. Presenting, identifying, and characterizing MIE with a combination of biological and chemical approaches are ongoing activities (Allen et al. 2014). Ultimately, the future application of AOP is a biologic to develop a preclinical endpoint that represents a risk of death associated with impaired lung function, the potential to predict a decrease in lung function in people exposed to potential inhalation of toxic chemicals. Indicators can also be derived from AOP (Cahn and Siegel 2011; Benowitz 2014; McNeill 2016; Meernik and Goldstein 2016). In addition, these AOP-related in vitro tests may ultimately be useful for chemical toxic information (Scheffler et al. 2015a, b; Shivalingappa et al. 2016; Taylor et al. 2016; Terron et al. 2018). This will lead to more efficient application of the AOP knowledge to extrapolation, as well as quantitative chemistry and site-specific hazard evaluation (Groh et al. 2015). The newly proposed AOP could be provided for many purposes to make structure-activity relationships (SAR), new in vitro toxicity tests, and their priorities (Vinken 2013). Occupational exposure limit (OEL) settings are applied to data from published genetic and epigenetic studies, and demonstrate that the OEL could affect the occupational exposure by their toxicity (Gallo et al. 2011). Also, the toxic pathways from computational biology will focus on consistent physiological changes among similar functional groups of chemicals (Jennings 2013; MacKay et al. 2013). Extrapolation of animal data to predict health effects could result in physiological, anatomical, and metabolic pathways (e.g., cell type and composition, other biomodifying enzymes, and physiological changes in animals or even humans (BéruBé 2013); but this may not be sufficient to predict and manage potential side effects in humans (Chapman et al. 2010; Seidle et al. 2010). The discovery of AOPs from inhalations makes opportunities to develop in vitro and in silico tools to assess these endpoints, which could explain the expression of toxicity at the organism or population level (Villeneuve et al. 2014a, b). Although this has not yet been accepted by international regulatory bodies, it is a promising area of research (Clippinger et al. 2018a). The activities necessary to develop IATA to assess the inhalation toxicity of chemicals will be discussed, which will include information such as existing epidemiological and toxicity data, and the physicochemical properties of the test chemical, as well as a combination of non-test techniques. However, the best of these techniques will continue to evolve as more data become available, and as our understanding of the mechanisms of toxicity develops. In addition, acute inhalation toxicity, as well as many of the cellular systems and concepts described herein, can be applied to long-term repeated inhalation tests (Clippinger et al. 2018b).

New approaches for assessing worker health effects will be based on the mechanism of toxicity, dosing, in silico and in vitro tools, and the development of an adverse outcome pathway (AOP) for the broader implementation of these techniques, which will lead to an information gap. It will be optimized for non-animal techniques that investigate key events that help to address the data gap. The development of life sciences in the twenty-first century faces an unprecedented opportunity for the level of a dynamic systems and pathophysiology, taking into account the many trials and errors of new drug development and clinical research. This is a very important time to identify the many challenges and questions to be solved (Langley et al. 2015), and to begin a discussion of the issues that need to be considered. New models can also be developed using data collected from a number of sources. The US EPA Center for Computational Toxicology (https://comptox.epa.gov/dashboard/) provides a convenient model to accommodate the available models and their predictions, which can serve as a platform (Clippinger et al. 2018a). To improve the uncertainty of model prediction, it is important to carefully evaluate the variability of in vivo data with new model development, and exemplary protocols are being developed to develop in silico tools related to various endpoints (Myatt et al. 2018). In addition, 
it is necessary to develop an additional AOP to specifically express the onset of toxicity due to inhalation exposure, and it must be used to continuously establish AOP for the mechanism of inhalation toxicity.

\section{Social issues and research on workers' health in the semiconductor manufacturing}

The semiconductor industry can be called the crystal of high-tech industry (Williams et al. 2002; Yoon et al. 2020). In addition, despite the facts that chemicals in the semiconductor manufacturing have become a major social issue, that the detailed characteristics of chemicals used may change as semiconductor technology develops every year, and that the basic chemicals do not change, chemicals that affect detailed properties, for example, trace components used in the photo process, change, and this is difficult to understand, because most of them are designated as trade secret substances. This is reported to be because they are used in the form of a mixture. In addition, a lot of trade secret substances are included, but due to the characteristics of the semiconductor manufacturing process, many trade secret substances are included. Different semiconductor companies use different chemical product names and different components, and chemical information is not well disclosed, due to the technological protection characteristics of semiconductor manufacturing. As semiconductor production and technology advance, the type and quantity of chemical products change from time to time. In semiconductor manufacturing, high temperatures or high energy are used, in which case, reaction by-products may be generated (Yoon et al. 2020). Although basic chemicals do not change, chemicals that affect detailed properties, for example, trace components used in photo processing, change, and it is difficult to know, because most of them are designated as trade secret substances. Although chemicals are sometimes used as a single component, many products are used in the form of mixtures, and contain many trade secret substances. Due to the nature of the semiconductor manufacturing process, many confidential substances are included, but such information is difficult to grasp. Different semiconductor companies use different chemical product names and different components. Due to the technological protection characteristics of the semiconductor manufacturing, information on chemicals is not well disclosed. The type and quantity of chemical products change from time to time as semiconductor production and technology advances. In the semiconductor manufacturing, high temperatures or high energy are used, in which case reaction by-products may be generated.

This study complements the safety and health vulnerabilities of chemicals in the semiconductor manufacturing, contributes to solving social issues using big data, and improves the efficiency of the selection of substances subject to chronic and carcinogenic inhalation toxicity tests of chemicals in semiconductor manufacturing. I focused on the chemicals handled in semiconductor manufacturing, the key event relationship for each level of the "molecule $\rightarrow$ gene $\rightarrow$ cell $\rightarrow$ tissue $\rightarrow$ lesion $\rightarrow$ disease" sequence, which is the biological target of the chemical. By searching, analyzing, and linking the test data of Korea, I tried to find a way to improve the efficiency of human hazard evaluation. In the vision and strategy of toxicity testing in the twenty-first century, the importance of the AOP has emerged to be used in the evaluation of chemical hazards. To complement the safety and health vulnerabilities of chemicals in the semiconductor manufacturing, contribute to solving social issues using big data, and to improve the efficiency of selection of substances subject to chronic and carcinogenic inhalation toxicity tests of chemicals in the semiconductor manufacturing, I would like to focus on the chemicals handled by the company. I sought to find, analyze, and link test data on the key event relationships for each level that are biological targets of the chemicals, thereby preparing a plan to improve the efficiency of human hazard assessment.

\section{Materials and methods}

\section{Review of previous studies and AOP organization with public sites}

Previous studies of related domestic and foreign researchers were analyzed, and AOPs related to the chemicals in the semiconductor manufacturing were searched and organized with AOP DB construction and AOP proposals. In each process (wafer processing and chip assembly) of semiconductor manufacturing, examples of general toxicity paths for chemicals exposed to workers were collected, and the schematics for each path were shown in pictorial form. AOP analysis of semiconductor manufacturing chemicals was performed through data search input and analysis contents for each semiconductor manufacturing process, and sites used for AOP analysis of semiconductor manufacturing chemicals were organized.

\section{Searching the additional information for systematization of AOP from novel toxic information}

AOP analysis was conducted for 190 major chemicals by organizing representative cases of occupational diseases that occurred in semiconductor manufacturing. This was designed to help in the development of an additional AOP $\mathrm{DB}$, centering on references of the correlation with occupational disease recognition (Stressor AOP). I tried to obtain additional information to be found in this study based on the 
site, and an example of AOP provision. The concept of the WoE was reviewed in detail, the information and toxicity criteria were categorized, and additional information was searched for systematization of the AOP from DBs, such as CTD, Agency for Toxic Substances and Disease Registry (ATSDR), or stressor AOP (sAOP). Various pathology (tissue and blood) test data and data related to individual diseases were constructed, with the biomarkers specific to occupational diseases related to the semiconductor manufacturing process through three biomarkers and screening related to AOPs and diseases. The comparison was performed, and the verification of related occupational diseasespecific biomarkers and occupational disease-specific AOPs were analyzed. Through this, the semiconductor manufacturing chemicals analyzed by AOPs and the corresponding processes were presented. In connection with blood, histopathology, lesions, organs, and individual diseases, the 3rd stage was also used, using the sites "The Human Protein Atlas", and "KEGG Cancer Network". By intensive selection of pathways related to biomarkers across the range, the relationship between the detected biomarkers and diseases was examined. As a proposal for a specific biomarker related to chemicals in the semiconductor manufacturing, CTD was used, and the analysis of occupational disease-specific AOPs, key events relationship presentation, taxonomic classification for AOPs analysis, and AOPs analysis results of the chemical carcinogenicity estimation tool were presented.

\section{Detailed review of the AOP DB and a draft for disease prevention of semiconductor workers}

Along with detailed review of the results of the AOP DB, I considered the composition of the current AOPwiki and future use plans. The application, policy implications, and suggestions for health and inhalation toxicity were described. AOP analysis as a tool for estimating carcinogenicity (partial excerpts) was described, and AOP-related OECD serials were presented, and examples of appropriate strategy tests according to AOP target elements were presented by the IATA method. The engineering controls and working practices of the semiconductor manufacturing were reviewed, and in explaining some examples of predictive molecular tests and examples of future precision cancer prevention strategies, the limitations of occupational health activities to prevent diseases of semiconductor workers were presented, and also toxic effects patterns in AOP (Mode of action; MoA) or molecular initiation event (MIE) based on examples of chemical library preparation and skin sensitization. The concept of early responders in AOP and a new conceptual diagram were presented, and the OECD-led development process of AOP. The role of AOP in the data submitted to the regulatory body and examples of IATA were reviewed. Finally, the overall spectrum of cancer incidence and progression for the molecular diagnosis of oncology and the life test for cancer prevention was explained, and I presented a draft for the disease prevention of semiconductor workers through the example of carcinogenic AOP. Information of AOP DBs for chemicals in semiconductor manufacturing and their specific AOP were added to Table S1 to S3 in each Excel file.

\section{Results}

\section{Basic data searching in public sites}

Data searching and analysis contents for each semiconductor manufacturing process were summarized. AOP search and analysis related to chemicals (each same AO, process, and hazard) was performed, and the AOP analysis summary of chemicals in the semiconductor manufacturing was summarized. Sites, such as AOPwiki and AOP-KB, were used to search and verify existing AOPs. The results of the promotion were organized into an Excel file, and the results showed that there were 11 AOPs from 48 chemicals, such as AOP_36, 58, 60, 61, 66, 107, 150, 153, 163, 187, and 200. The results of this study are summarized in a schematic of the toxicity phenomenon caused by exposure to benzene, but the toxicity expression pathway (AOP) has not yet been developed. To analyze the correlation with the recognized cases of occupational diseases that occurred in the semiconductor manufacturing, the contents of Ref. (Lim 2018) were analyzed and considered, and according to this, Table S4 shows representative cases of recognition. As additional AOP searching, the stressor AOP (sAOP) DB contents were entered, and an emphasis was placed on building a DB to create new AOPs, through which 103 chemicals have AOPs, and 26 chemicals could be seen that have case evidence. The Excel files (.xlsx) were organized for AOP analysis results, and it was found that all 320 chemicals had 42 AOPs, and the major 190 chemicals corresponded to 11 AOPs.

\section{Searching for additional information and systematization of AOP}

The search for additional information for the systematization of AOP (research of data related to human and experimental animals for 190 chemicals) was performed using DBs, such as CTD, ATSDR, and sAOP. The systematization of AOP data was performed by summarizing the above results (Fig. 1, and Tables S1, S2). Data were constructed (for 40 chemicals), and examined in connection with 190 chemicals and blood and histopathology, lesions, organs, and diseases of individuals in humans and experimental animals. As a result, the substances corresponding to wafer processing were 25 types of 1-Methoxy, such as -2-propanol, 26 types 


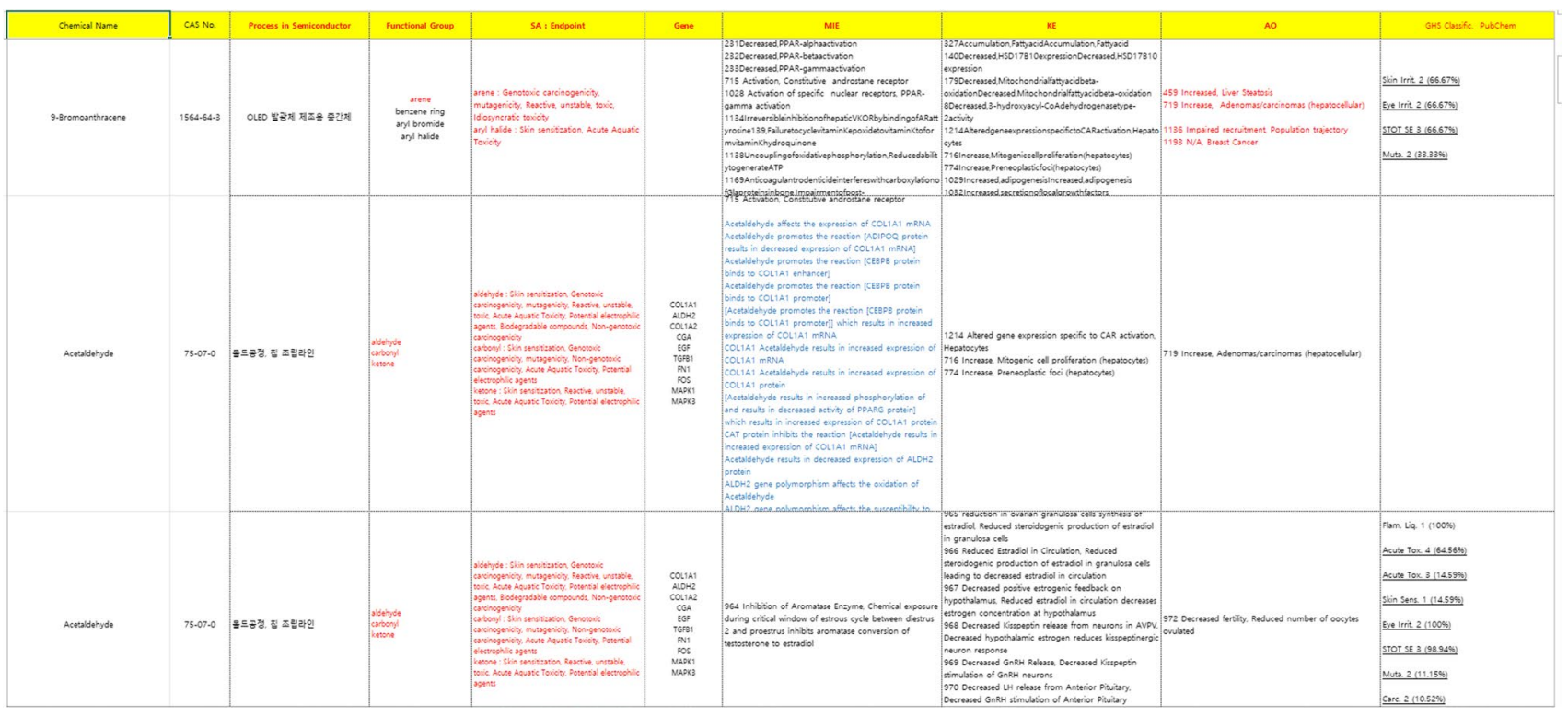

Fig. 1 Development of AOP DB performed by searching additional data with blue color. More data can be found in the attached Tables S1 and S2

such as 2-(2-Ethoxyethoxy) ethanol for chip assembly, and 11 types such as 1-Methoxy-2-propyl acetate for both lines (Table 1 and Fig. 2). To systematize the AOP data, various pathology (tissue and blood) test data and data related to individual diseases were constructed, and biomarkers specific to occupational diseases were related to the semiconductor manufacturing through three biomarkers and screening related to AOPs and diseases. Comparisons were performed, and the verification of related occupational disease-specific biomarkers and occupational disease-specific AOPs were analyzed (Table 2 and Fig. 3).

Through this, the semiconductor manufacturing chemicals analyzed by AOPs and the corresponding processes were presented, and three times using "The Human Protein Atlas" and "KEGG Cancer Network" sites in connection with blood, histopathology, lesions, organs, and individual diseases. By intensive selection of pathways related to biomarkers across the range, the relationship between the detected biomarkers and diseases was examined. As a proposal for a specific biomarker related to chemicals in the semiconductor manufacturing, the application of transcriptomics, that is, mRNA expression in AOPs, as well as the verification of its applicability as a biomarker as conducted by CTD was used, and the analysis of occupational diseasespecific AOPs, key events relationship presentation, taxonomic classification for AOPs analysis, and AOPs analysis results of the chemical carcinogenicity estimation tool were presented. To compare and search for biomarkers specific to occupational diseases of chemicals in the semiconductor manufacturing (41 out of 190), cross-validation by the attached Table 24 of the Enforcement Regulations of the
OSHAct and CTD data was performed. Table 3 below shows that 12 biomarkers at the CTD site can be identified as breast tumors (neoplasms). Table 4 analyzes AOPs specific to 50 chemicals associated with occupational diseases caused by semiconductor manufacturing, while Fig. 4 shows the analysis of occupational disease-specific AOPs and key events as well as taxonomic classification for AOPs analysis that could be found. Based on the above results, the AOP for a single substance is highly dependent on the quantity and quality of information related to chemicals, and the reliability of the AOP must be high, such as feedback, which can infer the AOP of other chemicals based on this. The pattern shown was reminiscent of the Möbius strip. On the other hand, it was judged that the AOP of a mixture makes it easier to identify the relationship (KER) and endpoint (AO) of the toxic effects of each chemical (Fig. 4). In addition, information on each chemical and WoE-based toxic data categorizing was separately organized, and Table S3 shows the entire data.

\section{AOPs correlation with cases of occupational diseases in the semiconductor manufacturing}

Lim's report entitled 'Analyzing Cases of Occupational Diseases of Semiconductor Workers' (Lim 2018) analyzed the correlation with cases of occupational diseases that occurred in the semiconductor manufacturing. According to the following, representative examples of recognition were found. "To put together these accreditation cases, there were 17 females by gender, far more than 9 males, and 14 out of 26 have already died. The largest number of workplaces was 
Table 1 Chemicals linked to diseases in each process

\begin{tabular}{|c|c|c|c|}
\hline Chemical Name & CAS No & Process in semiconductor & Etc \\
\hline 1-Methoxy-2-propyl acetate & $108-65-6$ & $\begin{array}{l}\text { Wafer processing, Chip assembly, } \\
\text { Photo (PR solvent) }\end{array}$ & \multirow[t]{11}{*}{ Common to all processes } \\
\hline Acetone & $67-64-1$ & $\begin{array}{l}\text { Overall process, Wafer processing, } \\
\text { Chip assembly, } \\
\text { Mold, Printing, Chip adhesion }\end{array}$ & \\
\hline Cresol & $\begin{array}{l}\text { o-Cresol 95-48-7 } \\
\text { p-Cresol 106-44-5 } \\
\text { m-Cresol 108-39-4 }\end{array}$ & $\begin{array}{l}\text { Wafer processing, Chip assembly, } \\
\text { Mold, Photo (PR solvent), Mold }\end{array}$ & \\
\hline Ethanol & $64-17-5$ & $\begin{array}{l}\text { Wafer processing, Chip assembly, } \\
\text { Photo (PR solvent), Overall assem- } \\
\text { bly (Cleaning solution) }\end{array}$ & \\
\hline Hydrogen peroxide & $7722-84-1$ & $\begin{array}{l}\text { Wafer processing, Chip assembly, } \\
\text { Chip adhesion (liquid), Wet etching, } \\
\text { wet cleaning, Plating }\end{array}$ & \\
\hline Isopropyl alcohol & $67-63-0$ & $\begin{array}{l}\text { Wafer processing, Chip assembly, } \\
\text { Photo (PR solvent), Cleaning solu- } \\
\text { tion (PM etc.), Maintenance, Wash- } \\
\text { ing, Diffusion (liquid, Plating etc.) }\end{array}$ & \\
\hline$n$-Butyl acetate & $123-86-4$ & $\begin{array}{l}\text { Wafer processing, Chip assembly, } \\
\text { Photo (PR solvent), Testing etc }\end{array}$ & \\
\hline Nitric acid & $7697-37-2$ & $\begin{array}{l}\text { Wafer processing, Chip assembly, Wet } \\
\text { etching, Grinding, Wet cleaning, } \\
\text { Plating }\end{array}$ & \\
\hline Potassium hydroxide & $1310-58-3$ & $\begin{array}{l}\text { Wafer processing, Chip assembly, } \\
\text { BSG (Grinding), Plating }\end{array}$ & \\
\hline Sulfuric acid & 7664-93-9 & $\begin{array}{l}\text { Wafer processing, Chip assembly, Wet } \\
\text { etching, Wet cleaning, Plating }\end{array}$ & \\
\hline Tetramethyl ammonium hydroxide & $\begin{array}{l}75-59-2 \\
10,424-66-5 \text { (Trihydrate) } \\
10,424-65-4 \text { (Pentahydrate) }\end{array}$ & $\begin{array}{l}\text { Wafer processing, Chip assembly, } \\
\text { Photo (developer), Rear Grinding }\end{array}$ & \\
\hline 1-Methoxy-2-propanol & $107-98-2$ & Wafer processing, Photo (PR solvent) & \multirow{13}{*}{$\begin{array}{l}\text { Specific to the wafer processing } \\
\text { process }\end{array}$} \\
\hline 2-(2-Aminoethoxy)-ethanol & $929-06-6$ & Wafer processing & \\
\hline 2-Ethoxyethanol & $110-80-5$ & Wafer processing, Photo (PR solvent) & \\
\hline 2-Heptanone & $110-43-0$ & Wafer processing, Photo (PR solvent) & \\
\hline Catechol & $120-80-9$ & Wafer processing, Photo (PR removal) & \\
\hline Dibutyl ether & $142-96-1$ & Wafer processing, CVD & \\
\hline Ethylene glycol & $107-21-1$ & $\begin{array}{l}\text { Wafer processing, Dry etching, CVD, } \\
\text { Ion implantation (Past } 6 \text { inches) }\end{array}$ & \\
\hline Gamma-Butyrolactone & $96-48-0$ & Wafer processing, Photo & \\
\hline Methyl-2-hydroxy isobutyrate & $2110-78-3$ & Wafer processing & \\
\hline Methyl-3-methoxy propionate & $3852-09-3$ & Wafer processing, Photo (PR solvent) & \\
\hline Nitric oxide (Nitrogen monoxide) & $10,102-43-9$ & Wafer processing, Diffusion & \\
\hline Phosphoric acid & $7664-38-2$ & Wafer processing, Wet etching & \\
\hline Trimethyl phosphate & $512-56-1$ & Wafer processing, CVD & \\
\hline
\end{tabular}


Table 1 (continued)

\begin{tabular}{|c|c|c|c|}
\hline Chemical Name & CAS No & Process in semiconductor & Etc \\
\hline 2-(2-Ethoxyethoxy) ethanol & $111-90-0$ & Chip assembly, Mold & Specific to the chip assembly process \\
\hline 2-Butoxyethanol & $111-76-2$ & Overall Chip assembly & \\
\hline Acetaldehyde & $75-07-0$ & Mold, Chip assembly & \\
\hline Acetic acid & $64-19-7$ & $\begin{array}{l}\text { Washing, Wet etching, Etching (Wet, } \\
\text { liquid), Wafer processing, Washing } \\
\text { (Diffusion etc.), Wet etching }\end{array}$ & \\
\hline Ethyl acetate & $141-78-6$ & $\begin{array}{l}\text { Chip assembly, Chip adhesion, Mold, } \\
\text { Solder ball attachment, Printing (Ink } \\
\text { marking) Cleaning solution etc }\end{array}$ & \\
\hline Glycerol & $56-81-5$ & Solder ball attachment, Chip assembly & \\
\hline Heptane & $142-82-5$ & $\begin{array}{l}\text { Chip assembly, Mold, Photo (devel- } \\
\text { oper) etc }\end{array}$ & \\
\hline Methanesulfonic acid & $75-75-2$ & Chip assembly, Plating & \\
\hline Methyl isobutyl ketone & $108-10-1$ & Chip assembly, Mold etc & \\
\hline $\mathrm{N}$-Methyl-2-pyrrolidone & $872-50-4$ & $\begin{array}{l}\text { Chip assembly, Photo (PR removal, } \\
\text { developer) }\end{array}$ & \\
\hline Phenol & $108-95-2$ & Chip assembly, Mold, etc & \\
\hline Piperazine & $110-85-0$ & Chip assembly, Rear grinding & \\
\hline Polyethylene polypropylene glycol & $9003-11-6$ & Chip assembly & \\
\hline Tetrachloroethylene & $127-18-4$ & $\begin{array}{l}\text { Mold, Chip adhesion, Chip assembly, } \\
\text { Testing }\end{array}$ & \\
\hline Tetrahydrofuran & $109-99-9$ & $\begin{array}{l}\text { Chip assembly, Rear grinding, Solder } \\
\text { ball attachment, Mold, etc }\end{array}$ & \\
\hline Tin(II) methanesulfonate & $53,408-94-9$ & Chip assembly, Plating & \\
\hline
\end{tabular}

The 25 chemicals including 1-Methoxy-2-propanol are in wafer processing, 26 chemicals including 1-Methoxy-2-propyl acetate are in chip assembly

workers (14 persons) from S Electronics G Factory, and the most common job title was "operator" (17 persons), while the most common process was "etching" (8 persons). The working period was widely distributed between September 1983 and October 2014, ranging from 1 year 8 months to 22 years 11 months. Leukemia was the most common disease ( 7 patients), followed by aplastic anemia, breast cancer, brain tumor, multiple sclerosis (each 3 patients), lymphoma, lung cancer (each 2 patients), and ovarian cancer, infertility, and multiple neuropathy, respectively." (Lim 2018).

\section{The exposure scenarios and AOPs}

It is necessary to develop complex AOPs and secure exposure scenarios (combined exposure) based on information on the substances actually used in industrial sites. However, among the semiconductor manufacturing chemicals reported by Kim (2007), Table 5 shows the exposure scenarios for several chemicals that can show the exposure scenario (ES) in detail. As chemical management shifts from risk management to risk assessment, risk assessment of chemicals with exposure scenarios (ES) has become necessary. REACH is required to register all of the various uses for substances with high toxicity and high production volume for the responsibility of proving the safety of chemicals in humans and the environment, and risk assessment by developing exposure scenarios for each use. A report needs to be written. In semiconductor manufacturing, based on this, it will be necessary to support domestic workplaces and workers with risk assessment for chemicals, and to present relevant risk management techniques, and to establish a reasonable risk assessment system for chemical management. It is necessary to establish and present risk assessment and risk management methods according to exposure situations at any stage of the life of the chemical. To apply the adverse outcome pathway (AOP) to the workplace, it is important to present data on exposure scenarios for each chemical in semiconductor manufacturing, so that it can be used as chemical information for worker health protection. 


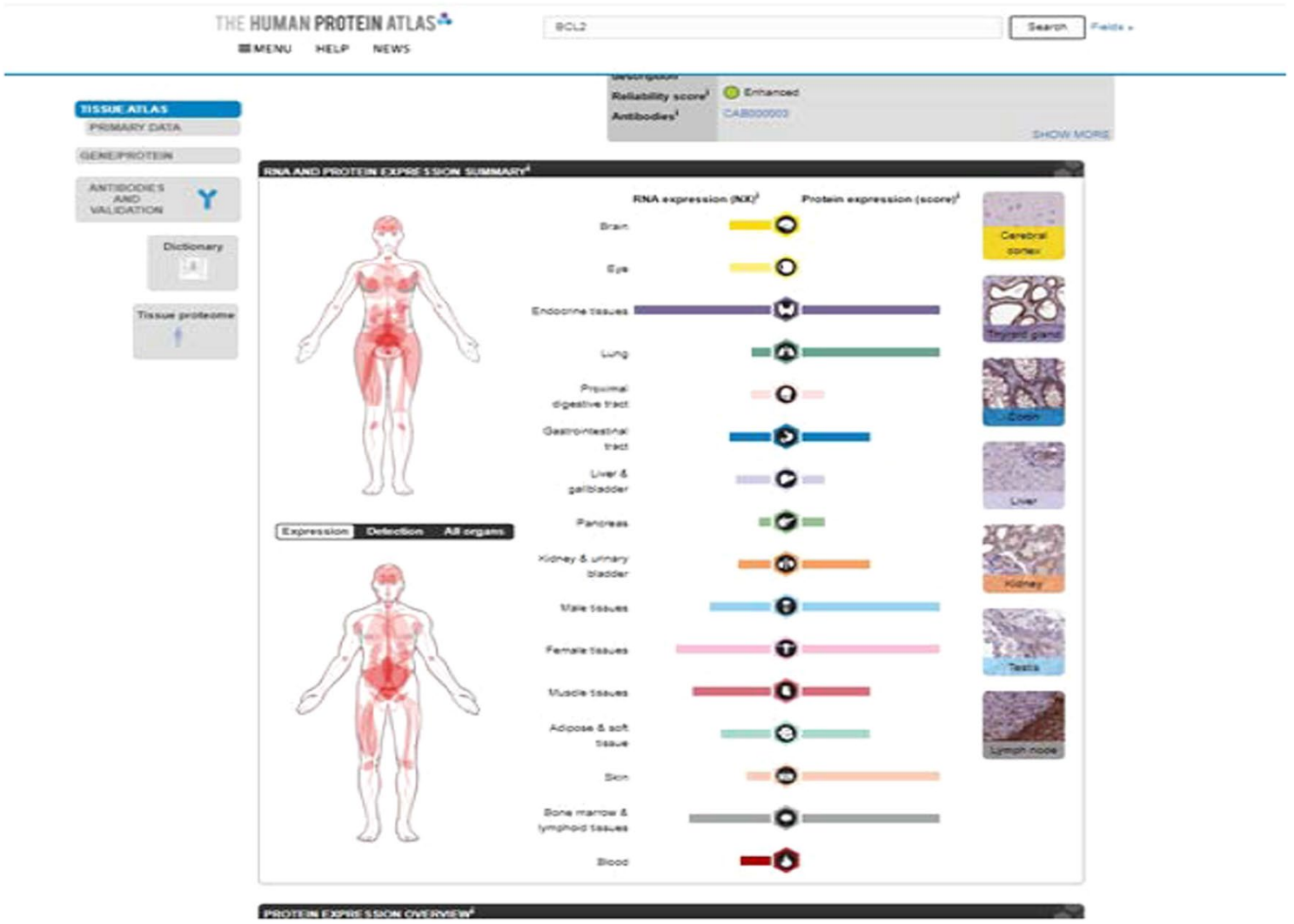

Fig. 2 Linkage with blood, histopathology, lesions, organs, and individual diseases. *Sourced from The Human Protein Atlas, https://www.prote inatlas.org/ Adapted with permission

\section{Discussion}

\section{Adverse outcome pathway (AOP) framework}

Correlation between the chemical structure and physicochemical and biological data for chemical toxicity prediction is used as a decision support tool using qualitative and quantitative structure-activity relationships (QSAR) and advanced computational methods. The in silico method has become common at the level of the development and regulation of toxicity assessment variables, modeling complex endpoints, such as organ toxicity, and using new AOPs. In in silico models, the endpoints for which toxicity predictions are modeled are dominated by a small number of MIEs and limited ADMEs, which describe the interactions between chemicals and biological targets, and are linked to toxicity endpoints through AOP (Ankley et al. 2010; Ankley and Edwards 2018). Engineered human genes, along with the most notable use of innovative in vitro and in silico tools, induced pluripotent stem cells (iPSCs), human cells derived from three-dimensional (3D) cell/tissue models, over the last decade, and the so-called "Human Gene Chip" was developed (OECD 2013a, b, c; Knudsen et al. 2015; Elmore et al. 2014).

\section{Application of AOP to occupational health}

The concept of AOP, based on exposure and risk assessment to product and environmental safety, can be used to understand adverse events as a sequence or process within biological systems, and to improve current risk assessment. Although the exact definition of MIE has not yet reached general consensus, the initial interactions between biomolecules or biological systems may have a causal relationship with outcomes through pathways, case studies, and problems. Thus, it is necessary to explore how to conduct further definitions, classifications, characterizations and risk assessments using a variety of chemical knowledge processes, suggesting the role of MIE studies in both in vitro and in silico tools (Allen et al. 2014). AOP is a key combination of appropriate in vitro models, and can provide techniques for systematic KE. Also, these AOP-based in vitro tests can be useful in identifying the risk of chemicals, and reducing their use. The future applicability of AOP predicts a decline in lung function exposed to inhaled toxic chemicals, and the proposed AOP will enable testing for compounds that may be toxic to humans upon inhalation (Heo et al. 2017). Biomarkers to develop preclinical endpoints indicating the risk of future disease or pulmonary dysfunction can also be 
Table 2 Screening of diagnostic biomarkers in Cancer network viewer

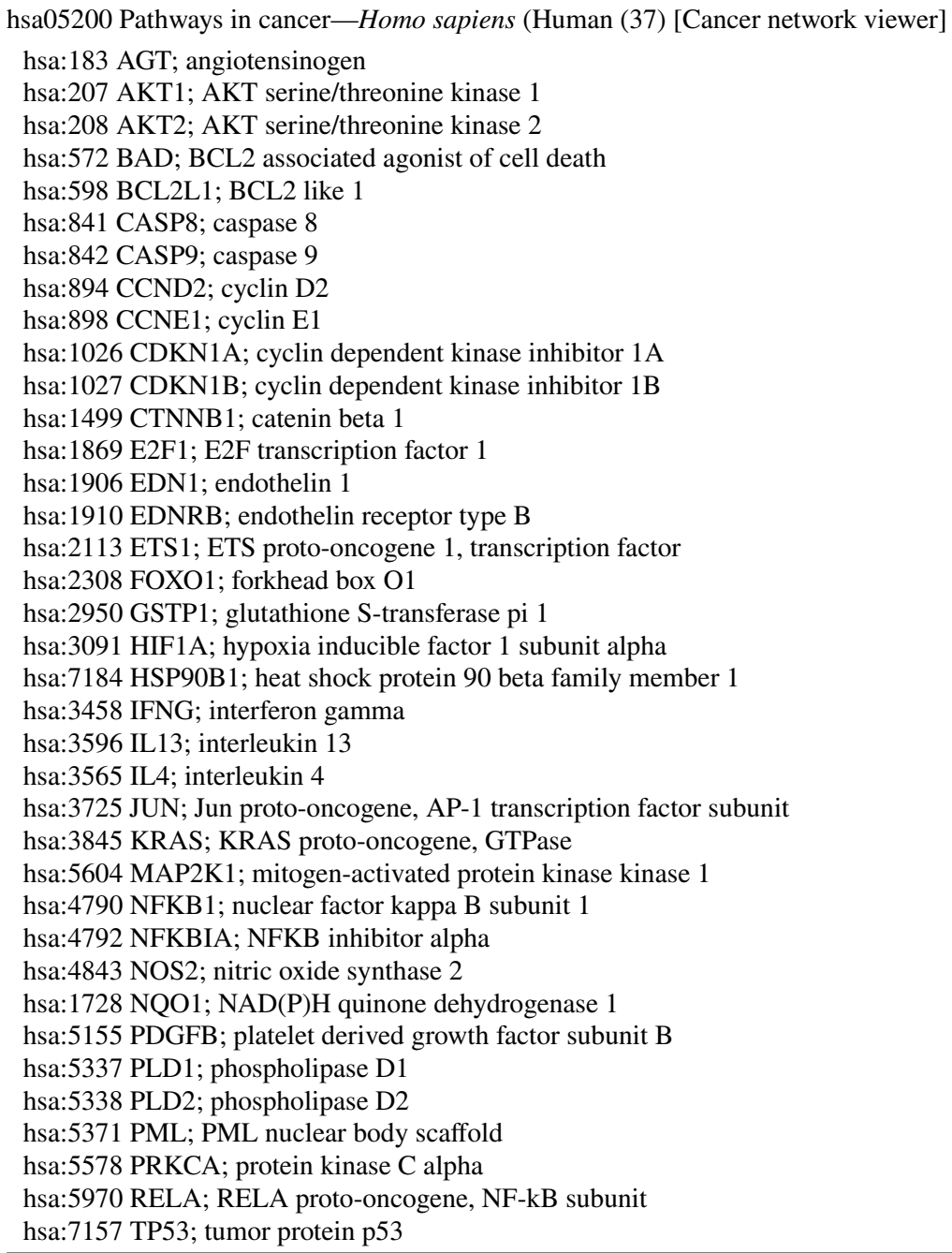

derived from these AOPs (Cahn and Siegel 2011; Benowitz 2014; Meernik and Goldstein 2016). Since AOP is a key combination of an appropriate in vitro model or analysis, it can provide a systematic KE technique, and AOP-based in vitro testing can be useful to reduce the in vivo tests. Toxicological pathways play an important role in integrating experimental data and knowledge derived from many sources, including evolution-based models. This makes it possible to apply the knowledge of AOP more efficiently, and also enables risk assessment for each site (Groh et al. 2015). The newly proposed AOP could be used for a variety of purposes, such as establishing SARs, researching and developing new in vitro toxicity, and improving priority strategies (Vinken 2013).

While genetics or epigenetics techniques for the prediction and identification of chemical hazards are evolving, further studies are needed to identify MOA and AOP at a limited level. Assessing gene-environmental interactions is the basis for using genetics or epigenetic studies, and in vivo and in vitro tools should be supplemented with occupational health and molecular epidemiology. The assessment should be designed to provide as much information as possible on the relationship between these mutations and toxic pathways, and when using genetic and epigenetic studies in occupational health issues, attention should be paid to social ethical implications. Ultimately, studies prior to genetics or epigenetics are used to assess occupational health, and the development of occupational exposure levels (OELs) should affect occupational exposure and the onset of toxicity (Gallo et al. 2011). Computational biology and the use of toxic pathways will increasingly focus on consistent physiological changes between groups of similar toxic chemicals (Jennings 2013; MacKay et al. 2013), the development of non-animal assays could provide more predictable tools or other in vivo observations using pathway-based machine information (BéruBé 2013), and should be sufficient to predict and manage potential human side effects (Chapman et al. 2010; Seidle et al. 2010; Zbinden and Flury-Roversi 1981). As a method to be applied directly to the semiconductor manufacturing process, constant monitoring of the 
Table 2 (continued)

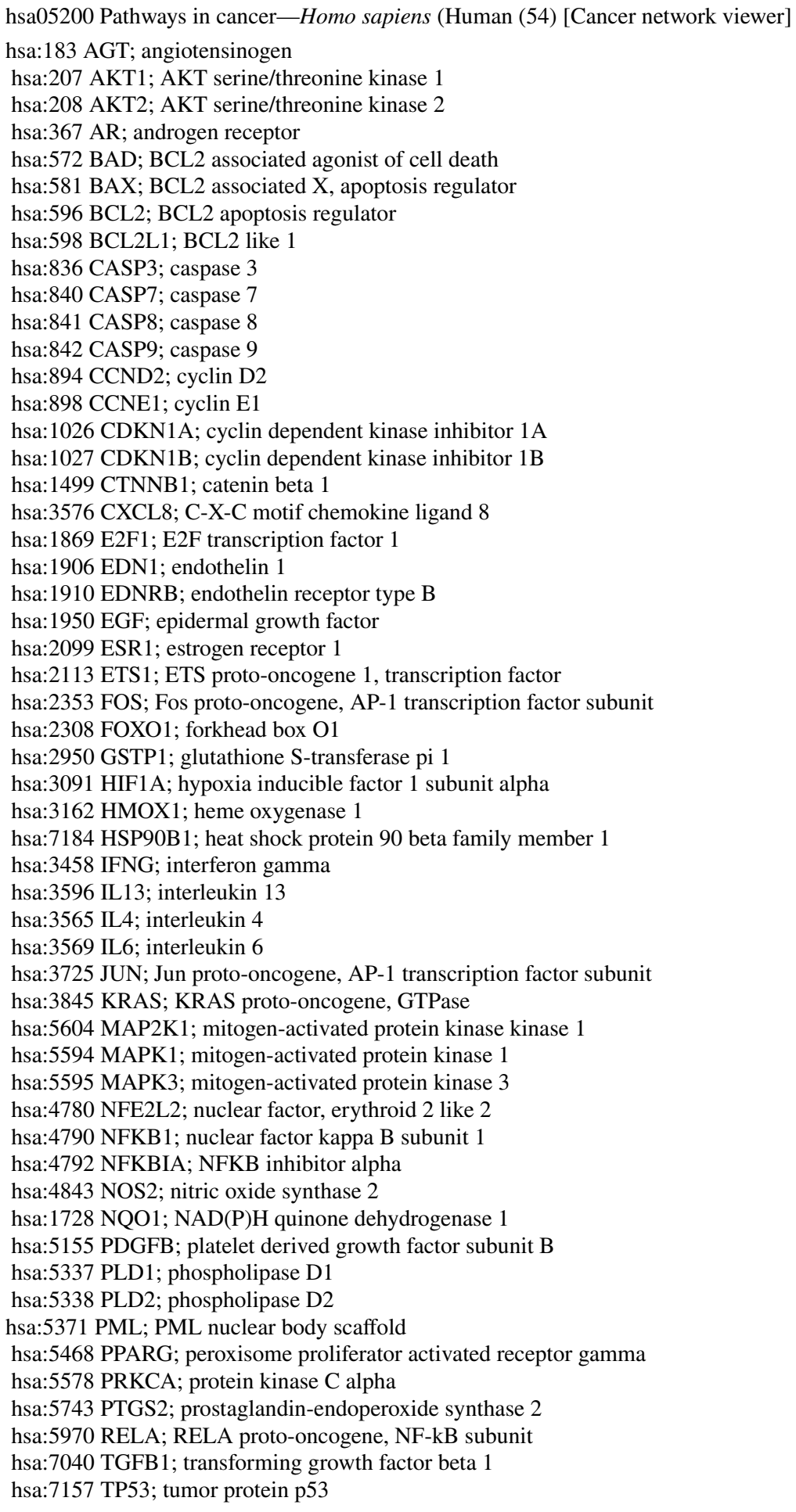

work environment (smart sensor monitoring) is achieved through constant measurement of exposure to chemicals [e.g., advanced facilities, such as AIoT (i.e., AI plus IoT), etc.], and constant contact with chemicals AOPs. By applying the constant monitoring, the health disorder prevention activities of workers can be carried out on a regular basis, and it is also necessary to construct a web-based system, such as AOP-KB, in the workplace of the future, so that the web-based AOP system can be used efficiently. AOP-KB is a website that provides data collection and registered AOPs through the establishment of a web-based platform hosted by the OECD. To this end, it will be important to benchmark 


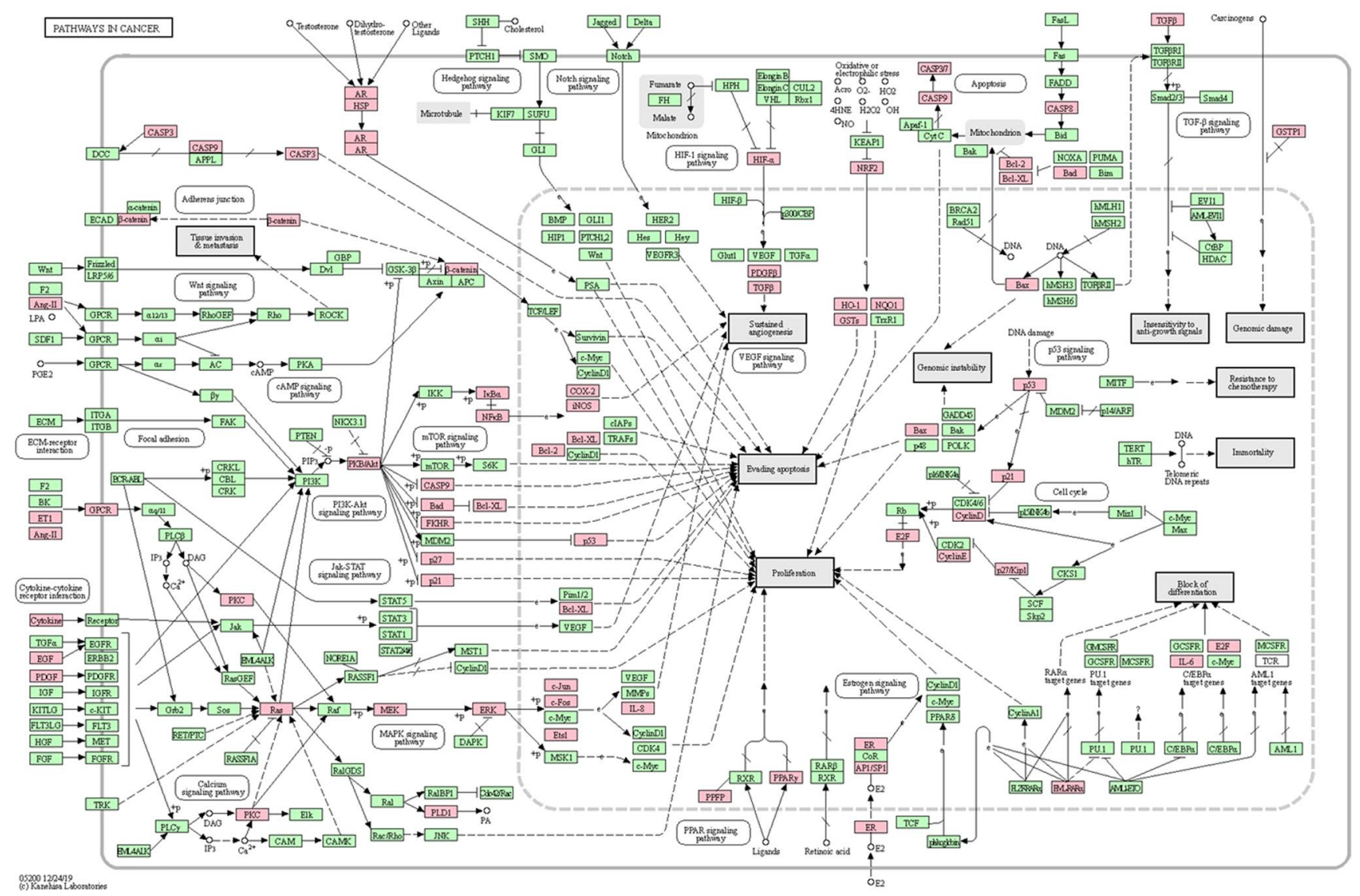

Fig. 3 Selection of the most related pathways to all diagnostic biomarkers, see https://www.genome.jp/kegg-bin/network_viewer. ${ }^{*}$ Sourced from KEGG (Kyoto Encyclopedia of Genes and Genomes), https://www.kegg.jp/ Adapted with permission

the cases of EU, Switzerland, Canada, UK, Japan, Belgium, Finland, Norway and Ireland, which are currently leading the establishment of AOP.

AOPwiki (https://aopwiki.org/), which was launched in 2014 through cooperation between the OECD, the EU, and the US EPA, encourages collaboration between researchers, and develops collaborative AOPs and modules that maximize the utility of workers. It provides the web-based opensource tool that is needed to consistently and effectively collect the AOP information required for chemical hazard assessment. The users can easily import existing knowledge or reported research information into AOP using a familiar web-based interface, and they will be able to freely exchange opinions on registered AOPs (Jeong and Choi 2017). AOPwiki could provide a list of different types of chemicals and approaches of AOPs, ranging from simple systems to more complex systems based on computers, web, or networks, where the establishment or laboratory is a management system that evaluates and updates individual chemicals and their corresponding AOPs. The module (software) should be optimized for chemicals management for research and development, industrial, and educational uses. Finally, the chemical management system (CMS) is developed to operate on the Microsoft Windows operating system, and it could use a user login and a barcode scanner compatible with the users' computers. It will also be useful for retrieving and managing information, such as entering new chemicals and their AOPs (Payne et al. 2020). Also, it will be an important development in AOPs, including the web-based AOP-KB as well as it will be required to improve use. Decision-makers in occupational safety and health distribute the web-based infrastructure created to support joint development, visualization, and the use of AOP-KB, etc. to business sites, and provide access to information accessible to disseminate AOP knowledge collected in accordance with international standards (Hecker and LaLone 2019).

\section{Application to AOP inhalation toxicity test}

The discovery of various AOPs following inhalation exposure will open the door to the development of in vitro and in silico tools to evaluate AOP-related endpoints that can explain toxic manifestations at the organism and/or population level (Villeneuve et al. 2014a, b). 
Table 3 Results of verification of occupational disease-specific biomarkers

\begin{tabular}{|c|c|c|c|c|}
\hline Name & Disease & $\begin{array}{l}\text { Direct } \\
\text { evidence }^{\mathrm{a}}\end{array}$ & Inference score & $\begin{array}{l}\text { Number of } \\
\text { references }\end{array}$ \\
\hline AHR & $\begin{array}{l}\text { Breast neo- } \\
\text { plasms }\end{array}$ & M & 134.87 & 404 \\
\hline BCL2 & $\begin{array}{l}\text { Breast neo- } \\
\text { plasms }\end{array}$ & M & 307.33 & 742 \\
\hline PARP1 & $\begin{array}{l}\text { Breast neo- } \\
\text { plasms }\end{array}$ & M & 285 & 701 \\
\hline TNF & $\begin{array}{l}\text { Breast neo- } \\
\text { plasms }\end{array}$ & M & 254.24 & 755 \\
\hline AKT1 & $\begin{array}{l}\text { Breast neo- } \\
\text { plasms }\end{array}$ & M & 250.16 & 704 \\
\hline CASP8 & $\begin{array}{l}\text { Breast neo- } \\
\text { plasms }\end{array}$ & M & 244.74 & 680 \\
\hline IFNG & $\begin{array}{l}\text { Breast neo- } \\
\text { plasms }\end{array}$ & M & 217.06 & 619 \\
\hline SOD2 & $\begin{array}{l}\text { Breast neo- } \\
\text { plasms }\end{array}$ & M & 213.22 & 691 \\
\hline CXCL8 & $\begin{array}{l}\text { Breast neo- } \\
\text { plasms }\end{array}$ & M & 208.81 & 604 \\
\hline NFKBIA & $\begin{array}{l}\text { Breast neo- } \\
\text { plasms }\end{array}$ & M & 204.82 & 647 \\
\hline CAT & $\begin{array}{l}\text { Breast neo- } \\
\text { plasms }\end{array}$ & M & 198.96 & 658 \\
\hline GSTP1 & $\begin{array}{l}\text { Breast neo- } \\
\text { plasms }\end{array}$ & M & 179.83 & 610 \\
\hline
\end{tabular}

aDirect evidence "M": this means a direct evidence for diagnostic markers in the CTD DB

This AOP tool is more reliable to evaluate target organ effects, and helps to understand the effects of certain toxic chemicals. As the understanding of the mechanisms of toxic progresses and the optimal technology continues to evolve, it has become a promising area of research that has not yet been approved by international regulatory bodies (Clippinger et al. 2018a), and many cellular systems with acute inhalation. The concept can be applied to long-term repeated inhalation studies (Clippinger et al. 2018b). A new approach is needed to assess the effects of inhaled toxic chemicals on workers' health, which is based on understanding the mechanisms of toxicity through in silico and in vitro tools. The development of AOP is used to address data gaps and investigate and optimize KE, and advances in the life sciences of the twenty-first century are a dynamic understanding of disease pathology and take into account ongoing research, from drug development to clinical practice (Langley et al. 2015). New technologies and drug development can also be applied to environmental issues, and to integrate and interpret data on pathological and physiological causes, studies focused on systems toxicology and human-specific models to understand AOP at various biological levels are needed (Jarabek 1995; US EPA 2009). It is important to carefully assess the variability of in vivo data dependent on the development of new models, and best practice protocols are being developed through in silico tools involving various endpoints (Myatt et al. 2018). In addition to the many AOPs associated with exposure, additional AOPs should develop specific toxic biomarkers that may arise from inhalation exposure, which is useful for the continued establishment of AOPs for inhalation toxic mechanisms, and AOP development has led to specific toxicity. It can be used to establish credibility in in vitro studies characterizing the likelihood and KE to cause. The development and implementation of nonanimal tests for inhalation toxicity and the acceptance of global regulations are encouraging the participation of many researchers, success in this field will make a platform to predict the inhalation toxicity, and these new tools will give more understandable mechanisms without animals.

As regulations for chemicals are strengthened, it has become necessary to evaluate the toxicity of numerous chemicals (including alternative chemicals) in a short time, and social demands for animal welfare, such as reduction in animal use, are increasing. Existing animal testing toxicity assessment systems test one species of chemicals on one experimental animal, and it is difficult to identify the hazards of numerous chemicals due to long-term/high cost/low efficiency. The new toxicity assessment system needs to be converted to an assessment method based on the analysis of the overall mechanism of the affiliated group through the experiment of a small number of chemicals. It changes the data acquisition method, and actively utilizes in silico and in vitro data-based alternative test methods for quick and large data acquisition, and is based on scientific models and leading the need for new methodologies that can effectively predict the hazards of chemicals.

\section{Proposal for pathological and safety management prevention of occupational diseases of chemicals in the semiconductor manufacturing}

Most epidemiological investigation evidence to date indicates that the semiconductor manufacturing has a negative impact on various developmental and reproductive processes. Although exposure to chemicals, particularly to glycol ethers, is frequently suspected as a causative agent, knowledge of the potential spectrum of certain factors that contribute to reproductive problems and their mechanisms is still very limited, making effective prevention efforts an important challenge (Kim et al. 2014). Different occupational diseases in the semiconductor manufacturing must be distinguished, and further research and sophisticated preventive management must be implemented to prevent cancer and reproductive toxicity in female workers, both in operator and maintenance workers. Semiconductor manufacturing is at the cutting edge of technology, science, and 
Table 4 Analysis of occupational disease-specific AOPs

\begin{tabular}{|c|c|c|c|}
\hline AOPs & MIEs (No.) & KEs (No.) & AOs (No.) \\
\hline AOP 200 Estrogen receptor activation leading to breast cancer & 1181 & $\begin{array}{l}1182 \\
1183 \\
177 \\
1088 \\
1187 \\
1188 \\
1189 \\
1190 \\
1191 \\
1192 \\
1194 \\
1195 \\
1196 \\
1197 \\
1198 \\
1213 \\
1239 \\
1240 \\
1241 \\
1242\end{array}$ & 1193 \\
\hline AOP 293 Increased DNA damage leading to increased risk of breast cancer & 1194 & $\begin{array}{l}1492 \\
1493 \\
1632 \\
1494 \\
1182\end{array}$ & $\begin{array}{l}185 \\
1192 \\
1193\end{array}$ \\
\hline AOP 294 Increased reactive oxygen and nitrogen species (RONS) leading to increased risk of breast cancer & 1632 & $\begin{array}{l}1182 \\
1492 \\
1493 \\
1494\end{array}$ & $\begin{array}{l}1194 \\
185 \\
1192 \\
1193\end{array}$ \\
\hline $\begin{array}{l}\text { AOP } 66 \text { Modulation of Adult Leydig Cell Function Subsequent Glucocorticoid Activation in the Fetal } \\
\text { Testis }\end{array}$ & $\begin{array}{l}653 \\
654\end{array}$ & $\begin{array}{l}655 \\
656 \\
657\end{array}$ & 505 \\
\hline AOP 67 Modulation of Adult Leydig Cell Function Subsequent to Estradiaol Activation in the Fetal Testis & $\begin{array}{l}658 \\
659\end{array}$ & $\begin{array}{l}655 \\
660 \\
656\end{array}$ & 505 \\
\hline AOP 68 Modulation of Adult Leydig Cell Function Subsequent to Alterations in the Fetal Testis Protome & 661 & $\begin{array}{l}655 \\
657 \\
656\end{array}$ & 505 \\
\hline $\begin{array}{l}\text { AOP } 107 \text { Constitutive androstane receptor activation leading to hepatocellular adenomas and carcinomas } \\
\text { in the mouse and the rat }\end{array}$ & 715 & $\begin{array}{l}1214 \\
716 \\
774\end{array}$ & 719 \\
\hline $\begin{array}{l}\text { AOP } 108 \text { Inhibition of pyruvate dehydrogenase kinase leading to hepatocellular adenomas and carcinomas } \\
\text { (in mouse and rat) }\end{array}$ & 724 & $\begin{array}{l}768 \\
209 \\
726 \\
769\end{array}$ & 719 \\
\hline $\begin{array}{l}\text { AOP } 117 \text { Androgen receptor activation leading to hepatocellular adenomas and carcinomas (in mouse and } \\
\text { rat) }\end{array}$ & 785 & 716 & 719 \\
\hline AOP 118 Chronic cytotoxicity leading to hepatocellular adenomas and carcinomas (in mouse and rat) & 786 & $\begin{array}{l}787 \\
774\end{array}$ & 719 \\
\hline AOP 37 PPARalpha-dependent liver cancer & 227 & $\begin{array}{l}1170 \\
716 \\
1171\end{array}$ & 719 \\
\hline AOP 153 Aromatase inhibition leading to ovulation inhibition and decreased fertility in female rats & 964 & $\begin{array}{l}965 \\
966 \\
967 \\
968 \\
969 \\
970 \\
971\end{array}$ & 972 \\
\hline
\end{tabular}


Table 4 (continued)

\begin{tabular}{|c|c|c|c|}
\hline AOPs & MIEs (No.) & KEs (No.) & AOs (No.) \\
\hline AOP 345 Androgen receptor (AR) antagonism leading to decreased fertility in females & 26 & $\begin{array}{l}286 \\
971\end{array}$ & 972 \\
\hline
\end{tabular}

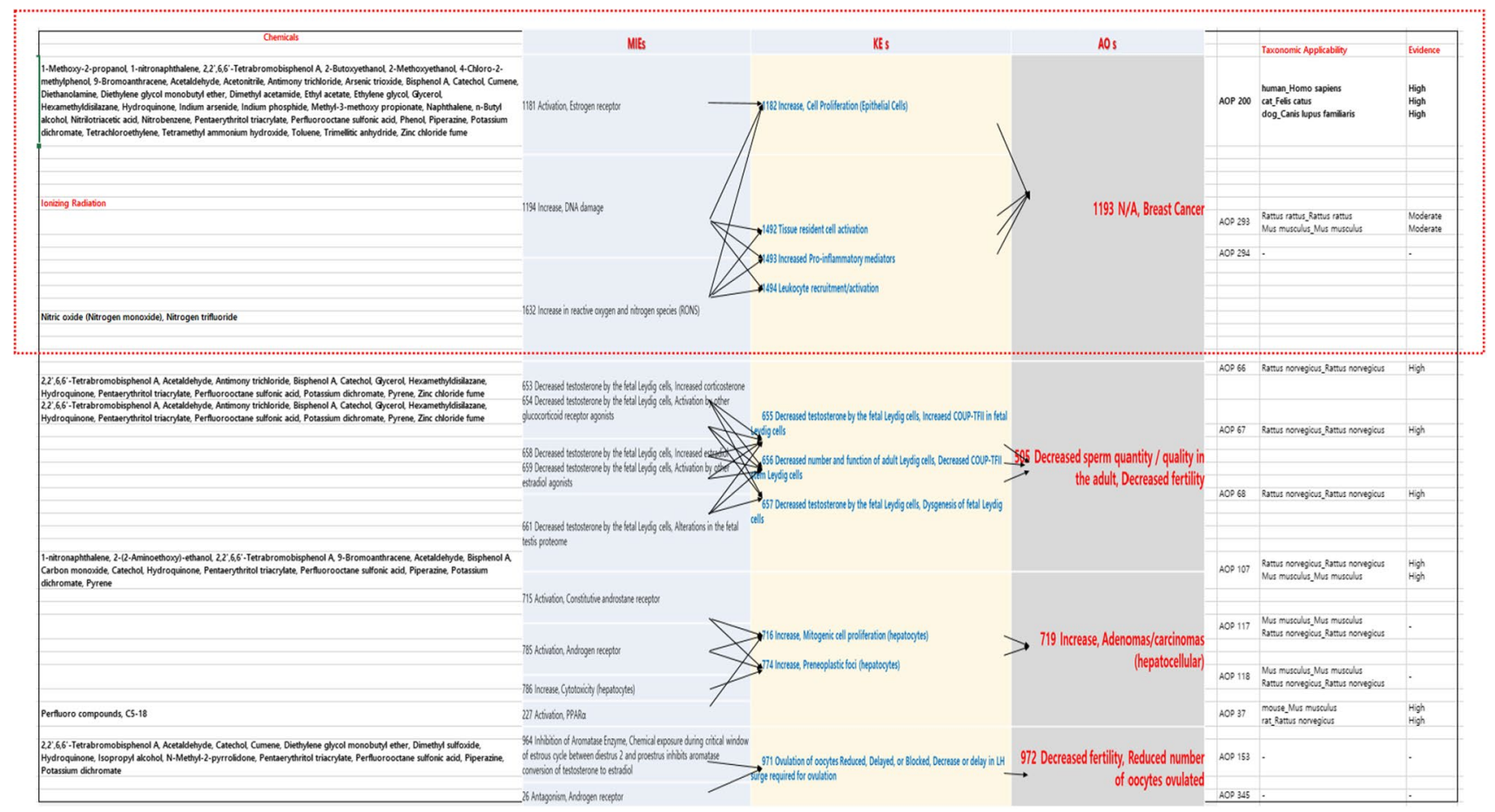

Fig. 4 Presentation of Occupational disease-specific AOPs and their key events relationships, as well as taxonomic classification for AOPs analysis

knowledge. This cutting-edge technology should also be applied to protect the health and environment of workers. Semiconductor manufacturing industry, the government, researchers, NGOs, and workers should work together to create a healthier and more sustainable work environment (Yoon 2012). Although the National Institute for Occupational Safety and Health (NIOSH) is working to reduce the risk of occupational cancer from gallium arsenide particles in the electronics industry, engineering control, proper work management, and appropriate personal protective equipment (PPE) must be used to prevent or significantly reduce the exposure (DHHS NIOSH 1987). Since gallium arsenic is used in the electronics industry to make certain semiconductor devices, its use has the potential to result in exposure to gallium arsenide particles (Wood 1986), and in animal studies, gallium arsenide is separated into gallium and arsenic in biological tissues. Inorganic arsenic has been identified as a carcinogen by NIOSH $(1975,1982)$, and gallium arsenic is considered a potential carcinogen.

Since Webb et al. (1984) reported that gallium was only found in the lungs and/or feces, some of the dissociated gallium remained in the lungs, and some were removed by the mucus cilia. The administration of inorganic arsenic to rats found similar changes in urine porphyrin (Martínez et al. 1983; Woods and Fowler 1978). Webb et al. (1986) suggested that after entering the body of rats, gallium arsenic is separated from arsenic. Yamauchi et al. (1986) found that organic products of arsenic metabolism (both dimethylarsinate and methylarsonic acid) were found with inorganic arsenic in urine and various tissues, and dissociation of gallium arsenic and the systemic distribution of inorganic arsenic appeared again. Since there are no NIOSH or ACGIH recommendations or OSHA standards specifically for gallium arsenic or gallium in animals (Webb et al. 1984; Webb et al. 1986; Yamauchi et al. 1986), showing the potential for exposure to arsenic by gallium arsenic in the electronics industry, the recommended NIOSH exposure limit for inorganic arsenic (REL; $2 \mu \mathrm{g} / \mathrm{m}^{3}$ with a ceiling of $15 \mathrm{~min}$ ) should be applied (NIOSH 1975, 1982). This is consistent with these conclusions that gallium arsenic dissociates into gallium and arsenic, and that inorganic 
Table 5 Several chemical exposure scenarios (ES) in semiconductor manufacturing Sourced by Kim (2007)

\begin{tabular}{|c|c|}
\hline Chemicals & Exposure scenario (ES) \\
\hline Arsine (CAS No. 7784-42-1) & $\begin{array}{l}\text { Exposure scenario (ES): Semiconductor manufacturing (MP process) } \\
\text { In the IMP (Ion implantation) process, work is automatically performed in a closed booth, and } \\
\text { the operator is performing tasks such as machine setting and equipment inspection. Workers } \\
\text { wear dust-proof clothes, masks, and dust-proof shoes, and a sealed local exhaust system is } \\
\text { installed in the workplace }\end{array}$ \\
\hline Phosphorus oxychloride (CAS No. 10025-87-3) & $\begin{array}{l}\text { Exposure scenario (ES): semiconductor manufacturing (site inspection) } \\
\text { Phosphorous oxychloride is used as a stable phosphorus supply in semiconductor factories. } \\
\text { Phosphorus acts as a dopant to create an N-type layer on a silicon wafer. Workers when } \\
\text { inspecting semiconductor manufacturing equipment and processes may be exposed to phos- } \\
\text { phorus oxychloride }\end{array}$ \\
\hline Dioxane (Diethyl dioxide) (CAS No. 123-91-1) & $\begin{array}{l}\text { Exposure scenario (ES): semiconductor manufacturing (site management) } \\
\text { During the semiconductor manufacturing process, photoresist (PR) is applied evenly to the } \\
\text { wafer surface, which is a light-sensitive material. The photosensitive agent used in this step } \\
\text { is made through the PAC process using dioxane, and is used in the process of applying a } \\
\text { photoresist, and exposure may occur. Workers may be exposed to dioxane due to leakage } \\
\text { during site management }\end{array}$ \\
\hline Chlorine (CAS No. 7782-50-5) & $\begin{array}{l}\text { Exposure scenario (ES): semiconductor manufacturing (etching work) } \\
\text { In semiconductor manufacturing, a crystal product is made using silicon or germanium, cut } \\
\text { to the required size, and a wafer is manufactured, and the wafer is made through a semicon- } \\
\text { ductor processing process that undergoes oxidation, etching, diffusion, ion implantation, } \\
\text { metallization, etc. Among them, the process that can be exposed to chlorine is an etching } \\
\text { process. However, since the process is a closed process, the possibility of respiratory and } \\
\text { skin exposure is low. Chlorine is easily vaporized even if it exists in the gaseous or liquid } \\
\text { state, so it is unlikely that it will remain in the skin }\end{array}$ \\
\hline 1,1,2-Trichloroethane (CAS No. 79-00-5) & $\begin{array}{l}\text { Exposure scenario (ES): Used as a washing agent in the semiconductor manufacturing process } \\
\text { Trichloroethylene, 1,1,2-trichloroethane, tetrachloroethylene, etc. are used as washing agents } \\
\text { in the semiconductor manufacturing process. Immerse the product in the washing liquid to } \\
\text { remove impurities. When washing a semiconductor using 1,1,2-trichloroethane, it may be } \\
\text { exposed to workers }\end{array}$ \\
\hline Boron trifluoride (CAS No. 7637-07-2) & $\begin{array}{l}\text { Exposure scenario (ES): For semiconductor manufacturing (doping) } \\
\text { Boron trifluoride, which is a dopant gas, is applied to the gate stack and the A surface layer } \\
\text { having the source-drain regions, and the source-drain regions are simultaneously diffusion- } \\
\text { doped. In this doping process, workers may be exposed }\end{array}$ \\
\hline
\end{tabular}

arsenic is biologically available and distributed throughout the body (Webb et al. 1984; Yamauchi et al. 1986). The discovery by Webb et al. (1984) suggested that workers could be exposed to arsenic, a known carcinogen, because there is no evidence that gallium arsenic reacts differently in humans. NIOSH recommends controlling worker exposure to gallium arsenide by the NIOSH REL $\left(2 \mu \mathrm{g} / \mathrm{m}^{3}\right.$ with a ceiling of $15 \mathrm{~min}$ ) for inorganic arsenic (NIOSH 1975, 1982). NIOSH also recommends estimating the concentration of gallium arsenic in the air by measuring it for arsenic using NIOSH method 7900 (NIOSH 1984). Table 6 outlines recommendations for minimizing the risk of exposure to gallium arsenide, and workers should be trained to be aware of the risk of exposure to gallium arsenide, and to improve engineering controls and work practices to reduce gallium arsenide or arsenic exposure in semiconductor manufacturing. Of course, PPE must be provided; and decontamination, waste removal, transportation, and disposal must also be provided.

\section{Use of AOP to prevent the occupational diseases of workers}

Over the years, many researchers have studied concentrations and other aspects of exposure to chemicals that adversely affect the human body, and numerous risk assessment animal and epidemiological studies have been reported for the effects of exposure to chemicals. To save time and money, researchers have worked to improve the tools for chemical risk assessment. After the first AOP concept was reported by Ankley et al. (2010), Ankley and Edwards (2018), as of August 2018, 243 AOPs and 1800 KEs have been registered. This AOP information can be freely used, operated, and developed in AOP-KB, a major AOP DB managed by the OECD, and the OECD has also launched AOP-KB in collaboration with the US EPA, the European Commission's Joint Research Center, and the US Army ERDC. AOPwiki provides a system for organizing published research information and the usable knowledge of each AOP, KE, KER, and stressors. Effectopedia is a modeling platform designed 
Table 6 Recommendations to minimize the risk of exposure to gallium arsenide

\section{Recommendations}

Awareness of risk

Engineering control and improvement of work practices PPE

\section{Contents}

The development of policies for the proper handling of gallium arsenide should be developed and implemented by health and safety personnel, and workers should be trained to be aware of the risks associated with gallium arsenide, and to make appropriate work practices and available engineering improvements. Workers should regularly collect samples from work areas that are likely to be exposed to gallium arsenide particles, or where surfaces are likely to be contaminated, which include crystal growth, crystal puller cleaning, crystal sawing, wafer grinding, and dicing. The sample should be analyzed for inorganic arsenic, and the analysis method described in NIOSH Analysis Method Manual, Method No. 7900 (NIOSH 1984) is used, and in some areas of the gallium arsenide process, both arsenic and gallium arsenic particles may be present

Recommendations for engineering controls and work practices are aimed at reducing gallium arsenic and arsenic exposure in the production area of gallium arsenide semiconductor manufacturing

Workers must provide and use disposable protective clothing, gloves, foot covers, and other suitable protective equipment necessary to prevent skin contact with gallium arsenide particulates. This protective device should be worn in the case of exposure to the crystal puller, crystal growth ampoule failure, and other gallium arsenide particles, and engineering controls are the preferred method to protect workers from exposure to gallium arsenide and arsenic, but NIOSH Respirators are also needed to protect workers in certain situations, such as emergencies involving the implementation, maintenance, and repair of engineering controls. Where engineering controls cannot adequately reduce exposures below REL to arsenic, workers should be provided with adequate respirators. If respiratory protection is required, employers must initiate a respiratory protection program that meets the OSHA requirements specified in 29 CFR 1910.134 (OSHA 2006), and a respiratory protection program approved by the Mines Safety and Health Administration (MSHA) and NIOSH includes at least respiratory. Assessment of workers' ability to perform tasks while wearing them, personnel training, suitability testing, and periodic environmental monitoring are included, and maintenance, inspection, and respiratory cleaning are also included. To implement an appropriate respiratory protection program, including the selection of the correct respiratory system, a knowledgeable person should be in charge of the program, and regularly evaluate the program. NIOSH recommends using only the most reliable respirators to protect workers from exposure to carcinogens. The following respirator is recommended for such a ventilator consisting of a supply air, front panel, and positive pressure ventilator with self-contained breathing apparatus. A combination of a full-face self-contained breathing apparatus or a full-face ventilator that operates in a pressure-demanding mode and a pressure-operated auxiliary self-contained breathing apparatus are recommended

Decontamination and waste disposal If gallium arsenic or arsenic can be removed from contaminated equipment, decontamination procedures should be established and performed. Where decontamination is not possible, the removal, transportation, and disposal of substances contaminated with gallium arsenide or arsenic must be in accordance with the regulations of the U.S. EPA, U.S. Department of Transportation, and/or state and local authorities. According to Negrei and Galateanu (2019), it is important to differentiate between workers with higher risk and lower risk, screening for both higher and lower risk is cost-effective, and it is also important to increase the level of participation by improving workers' awareness

Molecular diagnosis in everyday life test: Use of liquid biopsy
Strict medical surveillance of and various precautions against mutants susceptible to cancer must be taken, and cancers resulting from gonadal mutations often require significant modification of treatment strategies. The selection of customized anticancer drugs based on the potential for mutations has become an essential factor in cancer treatment, and molecular analysis is based on the administration of EGFR, BRAF, ALK, ROS1, and PARP inhibitors, as well as the use of other cytotoxic and target drugs. Liquid biopsies, i.e., analysis of circulating DNA or other tumor-derived molecules, offer great potential for the non-invasive monitoring of cancer diseases, drug-sensitive mutation analysis, and early cancer detection, while some tumor or tissue-specific mutant biomarkers that are used to diagnose primary cancer can be effectively utilized. The systematic classification of tumor molecular biomarkers increases the likelihood of discovering numerous new DNA and RNA-based markers of medical relevance for the development and application of AOP, and provides quantitative information on AOP elements using experimental data. A beta version is now available, and the Intermediate Effects DB processes chemical information, and informs the process by which chemicals trigger MIE or KE. AOP Xplorer is a calculation tool for the graphical representation of AOP, and Intermediate Effects DB and AOP Xplorer are currently being developed. All four systems share information through the AOP-KB hub, and each element of AOP$\mathrm{KB}$ is individually and independently arranged, making it useful for application in various studies. The OECD provides comprehensive management for AOP development and evaluation, the development of AOP is overseen by the OECD EAGMST, and AOPwiki is managed by the society 
for the advancement of AOPs. Since the publication of the first AOP titled "The pathway of toxicity to skin sensitization initiated by covalent binding to proteins", the OECD has published several reports and guidelines on AOP; and as of August 2018, eight AOP publications. There are 60 projects in the AOP development program work plan. Two examples of AOP related to carcinogenesis under development by AOP-KB are AOP 46 and AOP 220. These two AOPs have a confirmed MIE, and various cancers as AOs. They are under EAGMST review, and citations and comments are ongoing. Using AOP to predict side effects caused by carcinogens presents important points in the prevention and treatment of cancer. These two AOP examples show that it is important to understand the early stages of AOP when the MIE and the first few KEs occur, and the main difference due to certain chemical/stress factors may be the action on the MIE, because the harmful effects of the body converge to similar KEs that produce tumors through cellular abnormalities. Therefore, in AOP, understanding the structure, properties, and in vivo (similar) mechanisms of a target chemical is a risk assessment and prevention, and further treatment. It should be considered first for application. As a conceptual tool, AOP describes an intuitive understanding of the side effects of chemicals. The goal of AOP is to accurately predict $\mathrm{AO}$ from stress factors, and the $\mathrm{AOP}$ approach has emerged as a future-oriented alternative to the existing paradigm in the field of risk assessment. The AOP approach was first introduced for ecotoxic risk assessment, but continues to be developed for widespread use in the overall risk assessment field. AOP applied to carcinogenic risk assessment to understand the impact of exposure to chronic toxic chemicals associated with carcinogenesis will be a very useful tool for predicting carcinogenicity, and based on these predictions it was thought ultimately to be able to provide a breakthrough in cancer prevention.

As a result of this study, the etching and washing processes were the main occupational diseases. These etching and washing processes are repeated processed in semiconductor processing, and due to the nature of the process of washing the chemicals on the wafer with other chemicals, various types of chemicals and materials are used in combination. It is also a process in which cancer damage reports are concentrated (Kong 2012). Points to consider in exposure prevention management are: (1) spatial characteristics, (2) human characteristics, (3) types of harmful factors (as the semiconductor and electronics industries are undergoing rapid technological innovation, health suffers acute, chronic, and carcinogenic effects from the exposure to chemicals; the problem is that there is not enough time to study the effects, so a breakthrough change in exposure management based on the comprehensive precautionary principle has to be considered), and (4) On-site monitoring systems generally focus only on severe acute toxicity. A large number of chemicals are used without their harmfulness being confirmed, and legal management cannot be enforced, as there is no allowable exposure concentration.

In the electronics industry including semiconductor manufacturing, the production process after technology development is a labor-intensive industry, and thus requires a very flexible and inexpensive labor force (Kwon 2018). Many of the production workers in the semiconductor manufacturing are young women, who have a lot of difficulty in demanding improvement of their work environment, as they are relatively low in the hierarchies of age and gender. This is not a problem that can be ended by solving it in one region or country (Lee 2012). So long as semiconductors are used in modern society, the process of producing semiconductors will continue to be maintained, and unless workers are completely replaced by machines, etc., people will be exposed to chemicals, and the resulting risk issues will not disappear (Yoon 2012). Therefore, to prevent and prepare for future problems, it is necessary to examine the case of Korea in particular.

\section{List of substances proposed for AOP-based hazard assessment of chemicals in semiconductor manufacturing}

To conduct AOP-based hazard assessment in semiconductor manufacturing, it is necessary to first select an AOP project with a high degree of completion, and additional verification studies for the production of empirical data, and in vitro tests using various systems will be applicable. Here Table S5 presents a list of substances proposed for additional AOPbased hazard evaluation.

\section{Conclusion}

This study complements the safety and health vulnerabilities of chemicals in semiconductor manufacturing, contributes to solving social issues using big data, and improves the efficiency of the selection of substances subject to chronic and carcinogenic inhalation toxicity tests of chemicals in semiconductor manufacturing. I focused on the chemicals handled in semiconductor manufacturing, the key event relationship for each level of the "molecule $\rightarrow$ gene $\rightarrow$ cell $\rightarrow$ tissue $\rightarrow$ lesion $\rightarrow$ disease" sequence that is their biological target. By searching, analyzing, and linking the test data of Korea, I tried to find a way to improve the efficiency of human hazard evaluation. First, through the search and input of chemicals by semiconductor manufacturing process, I searched and analyzed for AOP related to chemicals (same AO, process, harmfulness), and verified the existing AOP oil search and confirmation (AOPwiki, AOP-KB). The Excel file arrangement 
(AOP_36, 58, 60, 61, 66, 107, 150, 153, 163, 187, 200) of the results of the promotion found that 48 chemicals had 11 AOPs. To examine the correlation with the recognition of occupational diseases, an additional AOP DB was searched. I found that 103 kinds of chemicals have AOPs, and 26 kinds have case evidence through the input of the stressor AOP (sAOP) DB contents. Through this study with Excel files for the AOP analysis, a total of 300 chemicals were found to have 42 AOPs, while 190 major chemicals had 11 AOPs.

As a result of resorting to AOPwiki for which AOP with WoE was established, for 190 substances by CTD, there were data and references searched on SAOP, and these contents were analyzed and used as KE. For 190 chemicals, data and reference contents searched on CTD and pathway studios were analyzed to classify similarities (e.g., same species, target organs, pathways, etc.), and KER validity was analyzed. By the experimental results of the references for collection and analysis, I was able to collect evidence for KE and KER. CTD, ATSDR, sAOP, etc. were used to search for additional information for the systematization of AOP (190 chemicals are related to human and laboratory animals). As a result of constructing and examining data related to 190 kinds of chemicals, blood and histopathology of humans and experimental animals, lesions, organs, and diseases of individuals, of semiconductor manufacturing, 25 chemicals including 1-Methoxy-2-propanol in wafer processing, and 26 chemicals including 1-Methoxy-2-propyl acetate in chip assembly could be screened and examined by the data for each process, biomarker, AOP, disease, etc.

Among the chemicals in semiconductor manufacturing, 41 out of 190 chemicals were searched for comparative biomarkers specific to occupational diseases, 12 biomarkers were found to be related to breast cancer by cross-validation with the attached Table 24 of the enforcement regulation of the OSHAct and CTD. AOP for 50 chemicals specific to the occurrence of occupational diseases are presented to the application of AOP as a tool for estimating carcinogenicity by the application of single chemicals and their mixtures. The pathological and safety-related proposal of the occurrence of occupational diseases caused by chemicals in the semiconductor manufacturing was presented, and these results were used in the predictive toxicity assessment project of chemicals, and policy making related to chemical hazards for workers and safety and health managers at work. Additional verification studies are needed by focusing on targets for which AOP information has been prepared through this study, and plans for specific outcomes that can be easily accessed and utilized by workers, epidemiological and clinical researchers, etc. are expected in the future.

Supplementary Information The online version contains supplementary material available at https://doi.org/10.1007/s13273-021-00139-4.
Acknowledgements This study was supported by the Korean Occupational Safety and Health Agency (Ulsan, Republic of Korea), the Ministry of Employment and Labor (Sejong, Republic of Korea), and a Grant-in Aid for chemical research (2020).

Author contributions K-T Rim designed the experiments and analyzed the results. All authors contributed to writing of the manuscript.

\section{Declarations}

Conflict of interest Kyung-Taek Rim declares that he has no conflicts of interest regarding the contents of this article.

Ethical approval The article does not contain any studies with human participants or animals performed by any of the authors, and it has been carried out in accordance with the institutional and national guidelines.

\section{References}

Allen TEH, Goodman JM, Gutsell S, Russell PJ (2014) Defining molecular initiating events in the adverse outcome pathway framework for risk assessment. Chem Res Toxicol 27:2100-2112

American Cancer Society (2018) Known and probable human carcinogens. https://www.cancer.org/cancer/cancer-causes/general-info/ known-and-probable-human-carcinogens.html. Accessed 23 Mar 2021

Ankley GT, Edwards SW (2018) The adverse outcome pathway: a multifaceted framework supporting 21 st century toxicology. Curr Opin Toxicol 9:1-7

Ankley GT et al (2010) Adverse outcome pathways: A conceptual framework to support ecotoxicology research and risk assessment. Environ Toxicol Chem 29:730-741. https://doi.org/10.1002/etc.34

Benowitz NL (2014) Emerging nicotine delivery products. Implications for public health. Ann Am Thorac Soc 11:231-235

BéruBé K (2013) Medical waste tissues-breathing life back into respiratory research. Altern Lab Anim 41:429-434

Bessems JG et al (2014) PBTK modelling platforms and parameter estimation tools to enable animal-free risk assessment: recommendations from a joint EPAA-EURL ECVAM ADME workshop. Regul Toxicol Pharmacol 68:119-139

Cahn Z, Siegel M (2011) Electronic cigarettes as a harm reduction strategy for tobacco control: A step forward or a repeat of past mistakes? J Public Health Policy 32:16-31

Chapman K et al (2010) The value of acute toxicity studies to support the clinical management of overdose and poisoning: a cross-discipline consensus. Regul Toxicol Pharmacol 58:354-359. https:// doi.org/10.1016/j.yrtph.2010.07.003

Clippinger AJ et al (2018a) Alternative approaches for acute inhalation toxicity testing to address global regulatory and non-regulatory data requirements: an international workshop report. Toxicol In Vitro 48:53-70. https://doi.org/10.1016/j.tiv.2017.12.011

Clippinger AJ et al (2018b) Pathway-based predictive approaches for non-animal assessment of acute inhalation toxicity. Toxicol In Vitro 52:131-145. https://doi.org/10.1016/j.tiv.2018.06.009

Cohen SM, Arnold LL (2011) Chemical carcinogenesis. Toxicol Sci 120(Suppl 1):S76-92

DHHS (NIOSH) (1987) Publication Number 88-100. Reducing the potential risk of developing cancer from exposure to gallium arsenide in the microelectronics industry

Elmore SA, Ryan AM, Wood CE, Crabbs TA, Sills RC (2014) FutureTox II: contemporary concepts in toxicology: "Pathways to 
prediction: in vitro and in silico models for predictive toxicology.” Toxicol Pathol 42:940-942. https://doi.org/10.1177/01926 23314537135

European Chemicals Agency (ECHA) (2018) Weight of evidence. https://echa.europa.eu/support/registration/how-to-avoid-unnec essary-testing-on-animals/weight-of-evidence. Accessed 23 Mar 2021

Gallo V et al (2011) Strengthening the reporting of observational studies in epidemiology-molecular epidemiology STROBE-ME: an extension of the STROBE statement. J Clin Epidemiol 64:1350 1363. https://doi.org/10.1016/j.jclinepi.2011.07.010

Gerloff K et al (2017) The Adverse Outcome Pathway approach in nanotoxicology. Comput Toxicol 1:3-11

Groh KJ et al (2015) Development and application of the adverse outcome pathway framework for understanding and predicting chronic toxicity: I. Challenges and research needs in ecotoxicology. Chemosphere 120:764-777. https://doi.org/10.1016/j.chemo sphere.2014.09.068

Hecker M, LaLone CA (2019) Adverse outcome pathways: moving from a scientific concept to an internationally accepted framework. Environ Toxicol Chem 38:1152-1163

Heo J et al (2017) Serum heavy metals and lung function in a chronic obstructive pulmonary disease cohort. Toxicol Environ Health Sci 9:30-35. https://doi.org/10.1007/s13530-017-0300-x

IARC (2018) Agents classified by the IARC monographs, volumes 1-122. https://monographs.iarc.fr/agents-classified-by-the-iarc/. Accessed 23 Mar 2021

Jarabek AM (1995) The application of dosimetry models to identify key processes and parameters for default dose-response assessment approaches. Toxicol Lett 79:171-184

Jennings P (2013) Stress response pathways, toxicity pathways and adverse outcome pathways. Arch Toxicol 87:13-14

Jeong J, Choi J (2017) Use of adverse outcome pathways in chemical toxicity testing: potential advantages and limitations. Environ Health Toxicol 33(1):e2018002

Kang DS et al (2018) Application of the adverse outcome pathway framework to risk assessment for predicting carcinogenicity of chemicals. J Cancer Prev 23:126-133. https://doi.org/10.15430/ JCP.2018.23.3.126

Kim SG (2007) Development of standardized model of exposure scenario for information communication in Korea. 2007 OSHRI Research Service Project. https://oshri.kosha.or.kr/oshri/publi cation/researchReportSearch.do? mode $=$ view\&articleNo $=62932$ \&article.offset $=10 \&$ articleLimit $=10 \&$ srSearchVal=\%EA $\%$ B $\%$ $80 \% \mathrm{EC} \% 88 \% 98 \% \mathrm{EA} \% \mathrm{~B} 7 \% \mathrm{BC} \& \mathrm{srSearchKey}=$ etc_text1\&srSea rchKey=etc_text 1 . Accessed 23 Mar 2021

Kim MH, Kim H, Paek D (2014) The health impacts of semiconductor production: an epidemiologic review. Int J Occup Environ Health 20:95-114

Knudsen TB et al (2015) FutureTox II: in vitro data and in silico models for predictive toxicology. Toxicol Sci 143:256-267. https:// doi.org/10.1093/toxsci/kfu234

Kong JO (2012) Working environment and experiences of diseases in semiconductor manufacturing. J Kor Soc Occup Env Hyg 22:3241. https://www.jksoeh.org/opensource/pdfjs/web/pdf_viewer. $\mathrm{htm}$ ?code $=\mathrm{J} 02201005$. Accessed 23 Mar 2021

Kwon JH (2018) Legal recognition of rare diseases of workers in semiconductor factories as industrial accidents: sociology of law of the production and approval of oppositional knowledge. Public interest and human rights 2018; 18 [in Korean] http://210.101.116.15/ kiss5/download_viewer.asp. Accessed 23 Mar 2021

Langley G et al (2015) Lessons from Toxicology: Developing a 21stCentury Paradigm for Medical Research. Environ Health Perspect 123:A268-A272. https://doi.org/10.1289/ehp.1510345

Lee JW (2012) Occupational diseases and environmental destruction by the borderless semiconductor manufacturing. Social movement
2012; 107:110-122 http://www.pssp.org/bbs/data/journal/7/107_\% EB\%B6\%84\%EC\%84\%9D_\%EC\%9D\%B4\%EC\%A7\%84\%EC\% 9A\%B0.pdf (in Korean)

Leist $\mathrm{M}$ et al (2017) Adverse outcome pathways: opportunities, limitations and open questions. Arch Toxicol 91:3477-3505. https://doi. org/10.1007/s00204-017-2045-3

Lim JW (2018) Analysis of cases of semiconductor workers' recognition of occupational diseases. In: Presentation for Seoul Regional Bar Association

MacKay C, Davies M, Summerfield V, Maxwell G (2013) From pathways to people: applying the adverse outcome pathway (AOP) for skin sensitization to risk assessment. Altex 30:473-486. https:// doi.org/10.14573/altex.2013.4.473

Martínez G, Cebrián M, Chamorro G, Jauge P (1983) Urinary uroporphyrin as an indicator of arsenic exposure in rats. Proc West Pharmacol Soc 26:171-174

McNeill A (2016) Should clinicians recommend e-cigarettes to their patients who smoke? Yes. Ann Fam Med 14:300-301

Meernik C, Goldstein AO (2016) Should clinicians recommend e-cigarettes to their patients who smoke? No. Ann Fam Med 14:302-303

Myatt GJ et al (2018) In silico toxicology protocols. Regul Toxicol Pharmacol 96:1-17. https://doi.org/10.1016/j.yrtph.2018.04.014

Negrei C, Galateanu B (2019) Ch. 46. Risk Factors as Biomarkers of Susceptibility in Breast Cancer. In: Biomarkers in toxicology, 2nd edn. Academic Press, Imprint of Elsevier, pp 850

NIOSH (1975) Criteria for a recommended standard: occupational exposure to inorganic arsenic; new criteria-1975. U.S. Department of Health, Education and Welfare, Public Health Service, Center for Disease Control, National Institute for Occupational Safety and Health, Cincinnati

NIOSH (1982) NIOSH testimony to U.S. Department of Labor: comments at the OSHA arsenic hearing. NIOSH policy statement. U.S. Department of Health and Human Services, Public Health Service, Centers for Disease Control, National Institute for Occupational Safety and Health, Cincinnati

NIOSH (1984) NIOSH Manual of analytical methods. In: Eller PM (ed) Criteria for a recommended standard: occupational exposure to inorganic arsenic (New Criteria - 1975). Volume 1, 3rd edn. U.S. Department of Health and Human Services, Public Health Service, Centers for Disease Control, Cincinnati

OECD (2012) Proposal for a template, and guidance on developing and assessing the completeness of adverse outcome pathways. OECD Publishing, Paris

OECD (2013a) Guidance document on developing and assessing adverse outcome pathways. OECD environment, health and safety publications-series on testing and assessment, No. 184. Paris, France

OECD (2013b) Adverse outcome pathway knowledge base (AOPKB). Series on testing and assessment No. 184. ENV/JM/ $\operatorname{MONO}(2013) 6$

OECD (2013c) Guidance document on developing and assessing adverse outcome pathways. OECD Environment, Health and Safety Publications. Series on Testing and Assessment No. 184. ENV/JM/MONO(2013)6

OECD (2016) OECD series on testing and assessment No. 260: guidance document on the use of adverse outcome pathways in Developing Integrated Approaches to Testing and Assessment (IATA). OECD, Paris

OECD (2018) Users' Handbook supplement to the Guidance Document for developing and assessing Adverse Outcome Pathways, OECD Series on Adverse Outcome Pathways, No. 1. OECD Publishing, Paris. https://doi.org/10.1787/5jlv1m9d1g32-en

Occupational Safety and Health Administration (OSHA) (2006) Major requirements of OSHA's respiratory protection standard 29 CFR 1910.134. OSHA Office of Training and Education, Rev 
Payne MK, Nelson AW, Humphrey WR, Straut CM (2020) The chemical management system (CMS): a useful tool for inventory management. J Chem Educ 97:1795-1798

Scheffler S, Dieken H, Krischenowski O, Aufderheide M (2015a) Cytotoxic evaluation of e-liquid aerosol using different lung-derived cell models. Int J Environ Res Public Health 12:12466-12474. https://doi.org/10.3390/ijerph121012466

Scheffler S et al (2015b) Evaluation of E-cigarette liquid vapor and mainstream cigarette smoke after direct exposure of primary human bronchial epithelial cells. Int J Environ Res Public Health 12:3915-3925. https://doi.org/10.3390/ijerph120403915

Seidle T, Robinson S, Holmes T, Creton S, Prieto P, Scheel J, Chlebus M (2010) Cross-sector review of drivers and available 3Rs approaches for acute systemic toxicity testing. Toxicol Sci 116:382-396. https://doi.org/10.1093/toxsci/kfq143

Shivalingappa PC, Hole R, Westphal CV, Vij N (2016) Airway exposure to E-cigarette vapors impairs autophagy and induces aggresome formation. Antioxid Redox Signal 24:186-204. https:// doi.org/10.1089/ars.2015.6367

Tanaka M, Inoue K, Shimada A, Mimura T, Takano H (2019) Effects of repeated pulmonary exposure to carbon nanotubes on lung function. Toxicol Environ Health Sci 11:120-124. https://doi.org/10. 1007/s13530-019-0396-2

Taylor M et al (2016) E-cigarette aerosols induce lower oxidative stress in vitro when compared to tobacco smoke. Toxicol Mech Methods 26:465-476. https://doi.org/10.1080/15376516.2016.1222473

Terron A et al (2018) An adverse outcome pathway for Parkinsonian motor deficits associated with mitochondrial complex I inhibition. Arch Toxicol 92:41-82. https://doi.org/10.1007/ s00204-017-2133-4

US EPA (2009) Risk and technology review (RTR) risk assessment methodologies: for review by the epa's science advisory board. Case Studies-MACT I Petroleum Refning Sources Portland Cement Manufacturing (EPA-452/R-09-006)

US EPA (2018) Human health risk assessment. https://www.epa.gov/ risk/human-health-risk-assessment. Accessed 23 Mar 2021

US National Research Council (2007) toxicity testing in the 21 st century: a vision and a strategy. p. 216 https://doi.org/10.17226/ 11970 (ISBN 978-0-309-10992-5)

Villeneuve DL et al (2014a) Adverse outcome pathway (AOP) development I: strategies and principles. Toxicol Sci 142:312-320. https://doi.org/10.1093/toxsci/kfu199
Villeneuve DL et al (2014b) Adverse outcome pathway development II: best practices. Toxicol Sci 142:321-330. https://doi.org/10. 1093/toxsci/kfu200

Vinken M (2013) The adverse outcome pathway concept: A pragmatic tool in toxicology. Toxicology 312:158-165

Webb DR, Sipes IG, Carter DE (1984) In vitro solubility and in vivo toxicity of gallium arsenide. Toxicol Appl Pharmacol 76:96-104

Webb DR, Wilson SE, Carter DE (1986) Comparative pulmonary toxicity of gallium arsenide, gallium (III) oxide, or arsenic(III) oxide intratracheally instilled into rats. Toxicol Appl Pharmacol 82:405-416

Williams ED, Ayres RU, Heller M (2002) The 1.7 kilogram microchip: Energy and material use in the production of semiconductor manufacturing. Environ Sci Technol 36:5504-5510

Wood PM (1986) Living in a material world: the gallium arsenide wafer market. Solid State Technol 29:120

Woods TS, Fowler BA (1978) Altered regulations of mammalian hepatic heme biosynthesis and urinary porphyrin excretion during prolonged exposure to sodium arsenate. Toxicol Appl Pharmacol 43:361-371

Worth A et al (2014) Alternative methods for regulatory toxicologya state-of-the-art review. European Union Reference Laboratory for Alternatives to Animal Testing (EURL ECVAM), Systems Toxicology Unit, Institute for Health and Consumer Protection, European Commission Joint Research Centre, Ispra, Italy

Yamauchi H, Takahashi K, Yamamura Y (1986) Metabolism and excretion of orally and intraperitoneally administered gallium arsenide in the hamster. Toxicology 40:237-246

Yoon CS (2012) Much concern but little research on semiconductor occupational health issues. J Korean Med Sci 27:461-464

Yoon C et al (2020) Harmful factors in the semiconductor manufacturing. Episteme (KNOU Press, Seoul, pp 269-272 (ISBN 978-89-20-03605-7)

Zbinden G, Flury-Roversi M (1981) Significance of the $\mathrm{LD}_{50}$ test for the toxicological evaluation of chemical substances. Arch Toxicol 47:77-99

Publisher's Note Springer Nature remains neutral with regard to jurisdictional claims in published maps and institutional affiliations. 